\title{
URBAN SPACES AND ITS REFLECTION IN THE DEVELOPMENT OF HOLY MECCA
}

\author{
Ahmed Mohamed A .Al-Hazmi \\ Sana'a University, Faculty of Engineering 00967-711114526- \\ 777134526 \\ hzmiyemen@hotmail.com
}

(Received February 27, 2008 Accepted October 10, 2009).

The increased demand for schemes to construct private buildings for citizens, particularly in Mecca, is a result of the enormous urban development in most cities of Saudi Arabia Kingdom, especially during the last decade, where the buildings are considered good investment (by rent) in Hajj seasons. This has overshadowed some schemes that deal with economy when the failure to provide squares and external parks didn't maintain the required balance between the building and the green areas.

The sense of responsibility to construct and build the land, and to use natural resources wisely and to try to limit the density of so-called asphalt forests that are represented by streets bridges and buildings, whether these are residential or civil, on the expenses of green areas, all that necessitates a trial to preserve what is left of open spaces in the urban fabric of holy Mecca.

And as holy Mecca has an important and distinctive value to Muslims that is due to the existence of much valued Kaabah, and while human nature has a tendency towards natural, environmental life, as well as towards greenery, water and beauty, there is a need, then, to restore the balance to the human environment.

As the design process of urban open spaces for cities depends on a full understanding of the balance between the needs of population, The local customs, and the requirements of the place, and as Mecca is one of the most important areas at the global, Arab and local level, this revealed gave the importance to this study.

The research also aims through its study of the urban spaces of Mecca at showing how to develop urban intellect in society at the concerned officials who work on the improvement and development of the areas of Al-Haram Al-Sharif. That in addition to the engineers who specialize in zoning and areas planning and architectural designers from an environmental perspective in order to create green spaces and decongesting parks that would develop the study region socially and environmentally. 


\section{الفراغات العمرانية واتعكاساتها على تتمية مكة المكرمة \\ د/احمد محمد /حمد ألمزمي

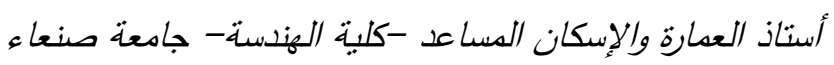 \\ 00967-711114526-777134526 \\ hzmiyemen@hotmail.com}

ملخص:

نظرا للتطور العمراني الهائل لمعظم مدن المملكة العربية السعودية وخاصة خلال السنوات الماضية فان زيادة الطلب على المخططات لإقامة المباني الخاصة للمواطنين وخاصة في مكة المكرمة (حيث تعتبر المباني فيها سلعة للاستثمار بالإيجار في مواسم الحج)، وقد أدى ذلك إلى وجود نوع من المخططات

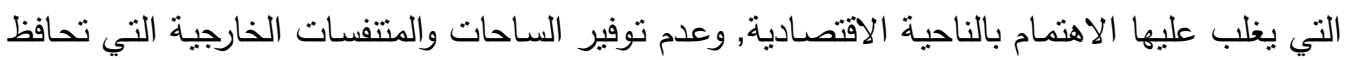
على التوازن المطلوب بين كفتي ميزان البناء والرقعة الخضراء.

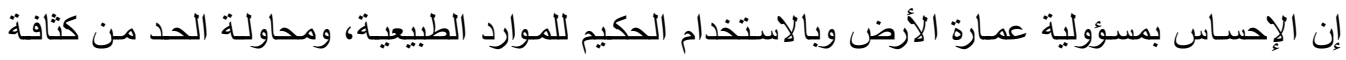
الغابات الإسفلتية المتمثلة في الثوارع والكباري وكذللك الغابات الأسمنتية المتمنتة في العمارات والمباني السكنية والمنشآت المدنية على حساب المناطق الخضراء كل ذلك أوجب ضرورة المحافظة على ما تبقى الهى من المساحات والفراغات المفتوحة المتقبة في النسيج العمراني لمكة المكرمة، ونظرا لما لمكة المكرمة

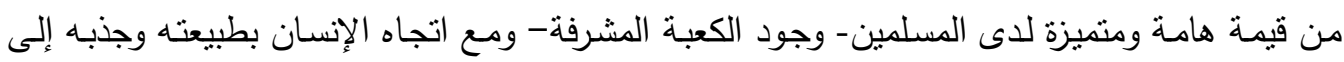
الحياة البيئية الطبيعية والى الخضرة والمـاء والجمال، فنجد انه بحاجة لإعادة التوازن الجمالي للبيئة الإنسانية.

ونظـرا لأن عمليـة تصـيم الفراغـات العمرانيـة الففتوحـة للمـدن تعتمــ على الفهم الكلي للموازنـة بـين احتياجات السكان والعادات والتقاليد المحلية وبين منطلبات المكان، ومـع كون مكة المكرمـة من أهم

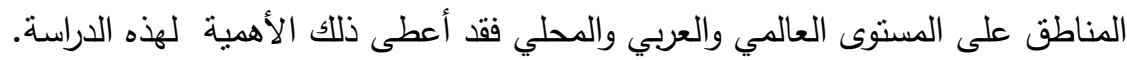
يهدف البحث من خـلال دراسـة الفراغـات العمرانيـة لمكـة المكرمـة إلى توضيح كيفيـة تطوير الفكر

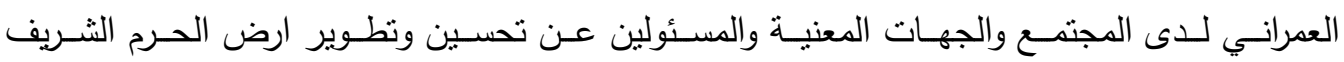

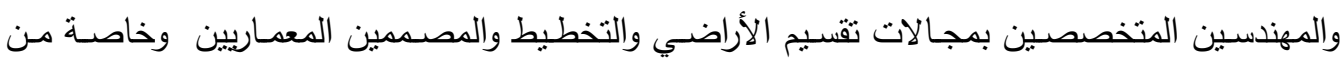
الناحيـة البيئية بحيث يتم إيجـاد متتفسـات ومسـاحات خضـراء من أجل تتميـة المنطقة المراد دراستتها اجتماعيا وبيئيا.

وقد اعتمدت الدراسـة في منهجيتها على توضيح الجوانب النظريـة المتعلقة بمفاهيم التتميـة العمرانيـة

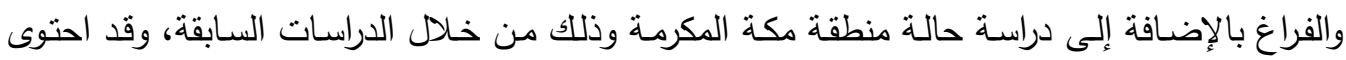


البحث على عرض مفـاهيم التتميـة العمرانيـة ودراسـة الفراغـات بالإضـافة إلى التعريف بمكة والفراغ العمراني فيها، وقد خلص البحث إلى مقترحات لجوانب التتمية فيها وتوصيات تتعلق بإيجاد بيئة عمرانية

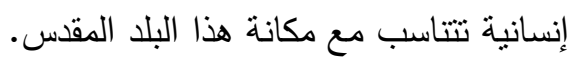

\section{1}

مـع تطور الحضـارات في البيئات المختلفة تطورت معها صيخ المنشـآت العمرانية والمعماريـة بهيئاتها التكوينية المختلفة,والتي ارتبطت فيما بعد بالظروف البيئية والاقتصادية والسياسية والمعتقدات الدينية السائدة وكذلك مقدار التقام التكنولوجي الذي حققه الإنسان والذي انعكس بالتبعية على العمارة والعمران

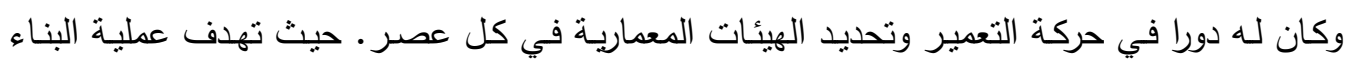
والتعمير في المقام الأول إلى خدمة الإنسان من كافة الجوانب، اذ اتجه الإنسان إلى توفير كل احتباجاته

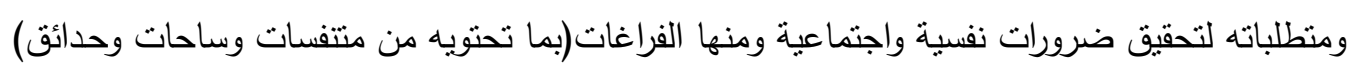
لتحقق له الراحة النفسية مع تحقيق المتطلبات الوظيفية.

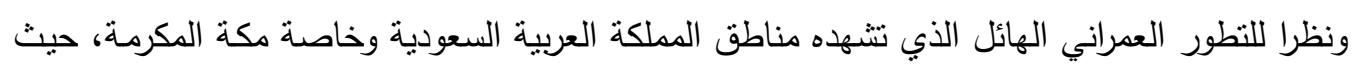

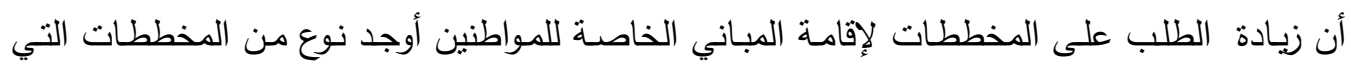

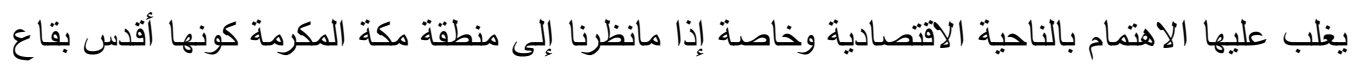

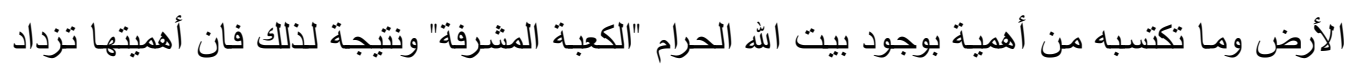

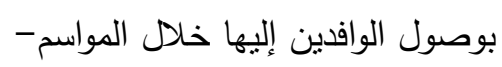
الحج-والعمرة- وما تكتظ به مكة من مباني سكنية بارتفاعاتها الثاهقة دون الاهتمام بالفراغات العمرانية

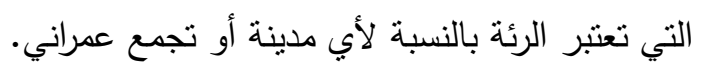
لذا جاءت هذه الدراسة كمحاولة لإعادة النوازن البيئي المطلوب للنسيج العبني العمراني لهذه البقعة المباركة من

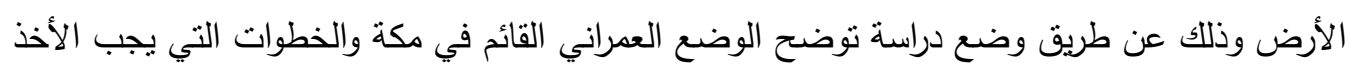

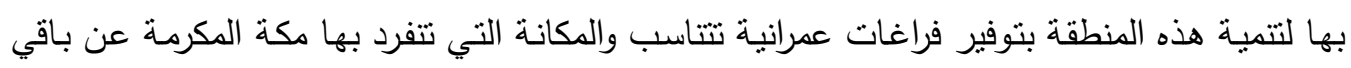
مدن المملكة.

\section{2.}

نظرا للزيادة المستمرة في أعداد الحجاج والمعتمرين فإن المدينة تشهد تزايداً في معدلات الإزدحامات

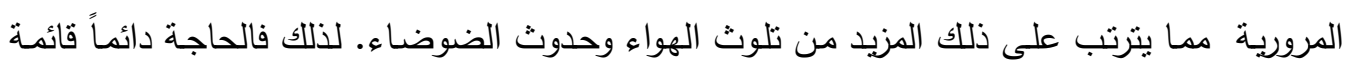

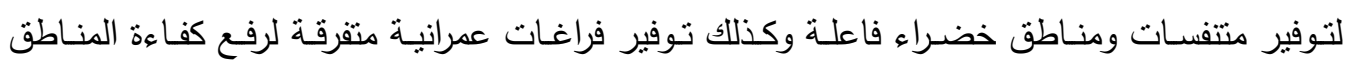
الخضراء والمتتفسات. 


\section{3.}

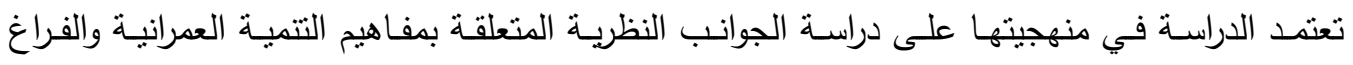

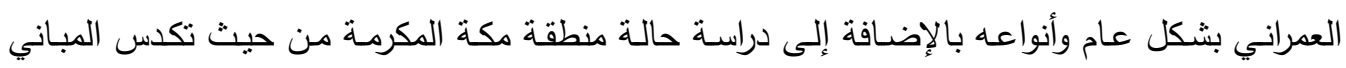
ووضع الفراغات العمرانية فيها وذذلك من خلال الدراسات السابقة في المكتبات أو الانترنت.

\section{4.}

\section{1-1-1 التمية: Development}

هي فعل مستمر وعمل منصل لا ينتهي بتحقيق غاية أو أهداف بعينها, إذ أن نقطة الوصول هي ذاتها

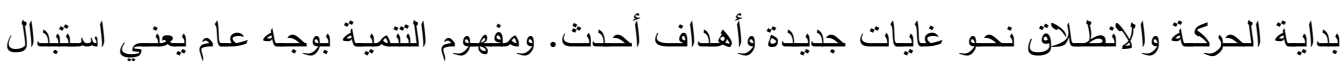
وإحلال واقع قائم بجديد مستهدف. بـانه - التنمية: هي سياسة الاعتماد على النفس على مدى زمني منظور لاستثمار طاقات كل أفراد المجتمع

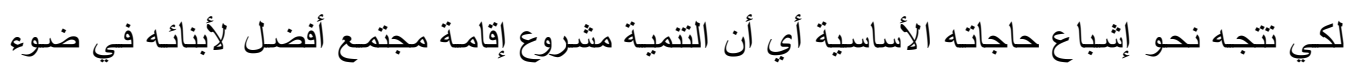

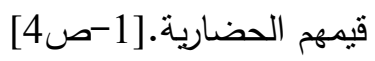
فالتتمية إذا هي عبارة عن عملية تغيير حضاري لها هو قائم بما هو مستهدف دون الإخلال بالهوية

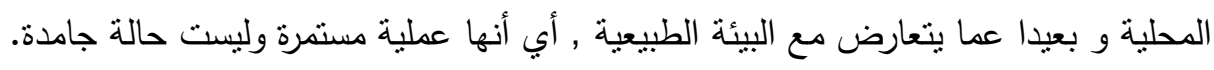

أ- التنمية المستدامة : n

هي إستراتيجية تسعى بواسطتها المجتمعات الإنسانية لتطوير سياساتها التتموية (الاقتصادية، السياسية، الاجتماعية، ...الخ) مما يعود بالنفع على نوعية الحياة والبيئة المحلية.

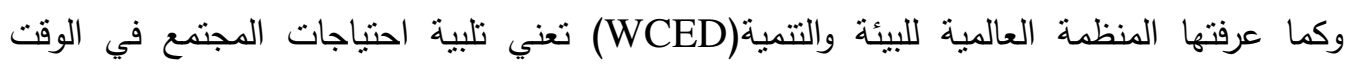

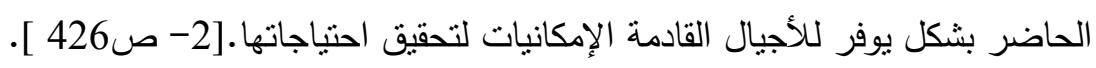

\section{ب- التنمية العمرانية:}

هي عبارة عن عملية مستمرة تقوم بها أجهزه مستقلة تتعامل مـع المتغيرات الاجتماعيـة والاقتصـادية

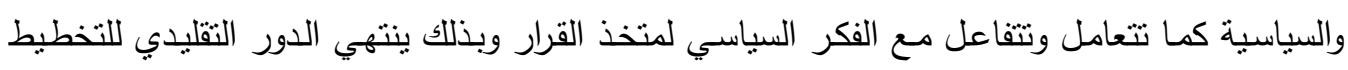

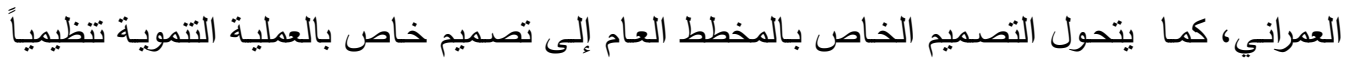

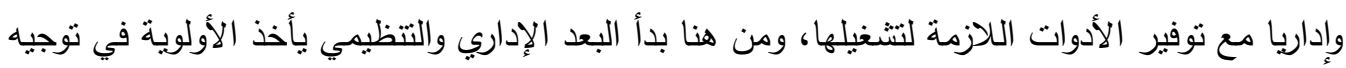

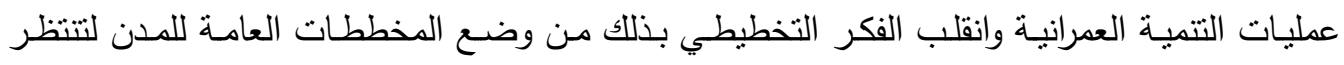


الأجهزة التي تنتطيع تتفيذها أو تحقق أهدافها إلى وضع الهياكل الإدارية والتتظيمية لأجهزة التخطيط

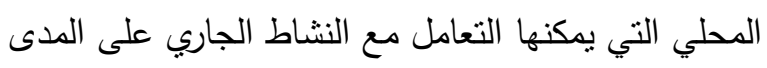

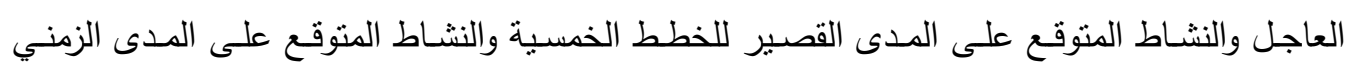

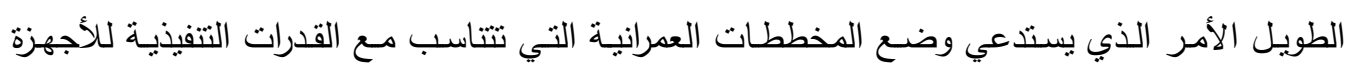
المحلية والتطلعات السياسية للمجالس المحلية في نفس الوقت حتى لا تبتعد أهداف التتمية العمرانية عن

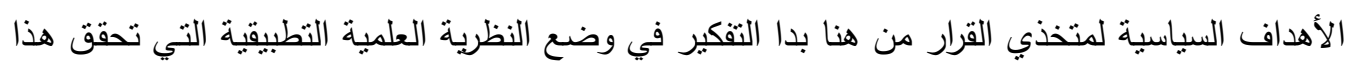

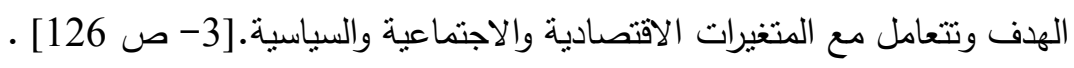

4-2-4 - العناصر العمرانية [4]: تصنف العناصر العمرانية إلى ثلاثة أنواع :

مكانيا: وتصنف كالتالي:-

- خارجية: وهي عناصر خاصة بحركة المشاة، وخاصة بحركة الآليات، وأخرى خاصة بالحركة الثبه آلية.

- انتقالية: وهي عناصر توزيعية، و تمهيدية، وأخرى بينية والمداخل والحارات.

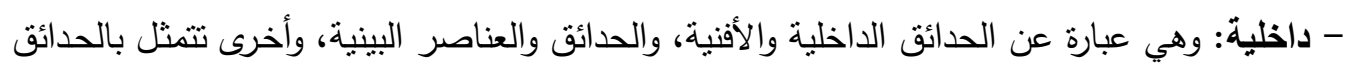
العامة والمنتزهات. وظفيا: وتصنف كالتالي:-

- خاصة: حيزات مغلقة - داخلية وغالبا ما تكون على مستوى مجموعة منازل أو فيلات.

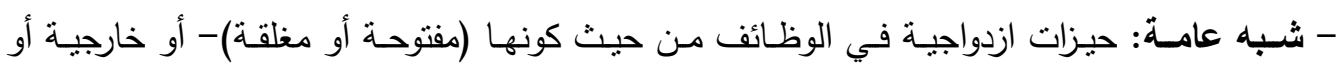
داخلية) على مستوى المجاورات السكنية.

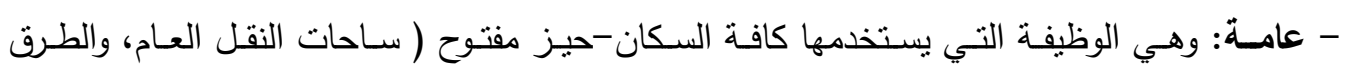
والساحات والمبادين العامة بالإضافة إلى كونها حدائق ومتنفسات عامة والتي نحن بصدد دراسته هنا.)

\section{حركيا (نوع الحركة):}

- عناصر عمرانيـة خاصـة بحركة المركبات: شبكة متكاملة مـع بعضها البعض لإتمام عملية الحركة وتتمنل بثلاثة أنواع: (الطرق والثوارع - المبادين - انتظار السيارات). - عناصر عمرانية خاصة بحركة شبه المركبات: شبكة حركة الدراجات.

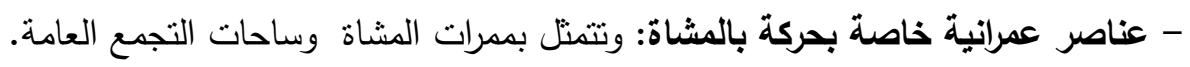

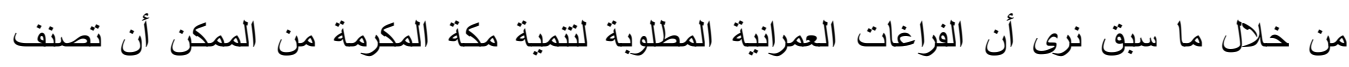

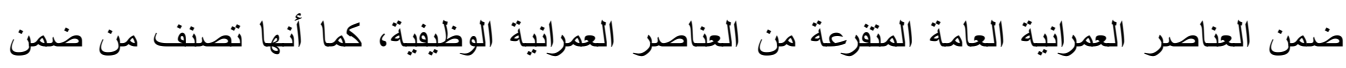
العناصر العمرانية الخاصة بحركة المشاة والتي تتفرع من العناصر العمرانية من حيث نوعية الحركة. 
4-4 - 3- الفراغات العمرانية:

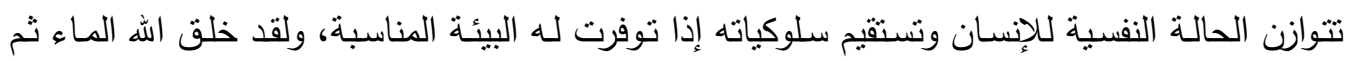

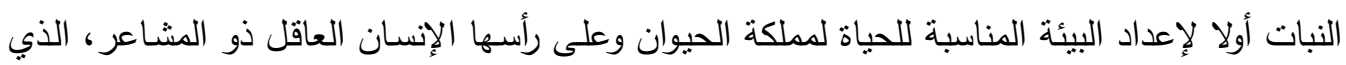

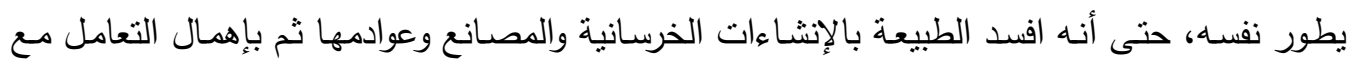
النفايات وقد كانت هناك مجتمعات متحضرة سبقتتا في إيجاد ذلك التوازن.

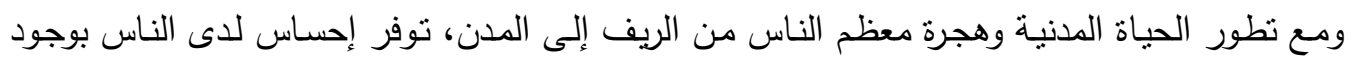

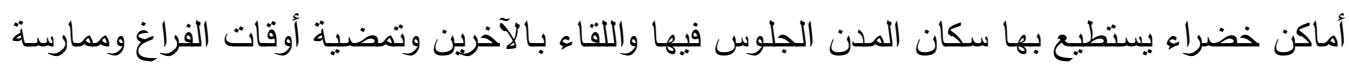
بعض الأنشطة الترفيهية مع أطفالهم بعيدا عن صخب السيارات في جو ممتع ومناظر جميلة.

الفراغ العمراني: هو شكل معين" form" لمنطقة عمرانية تجذب الناس بعضهم مع بعض لممارسة

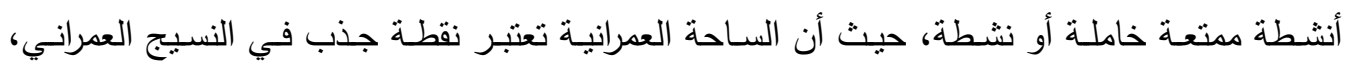

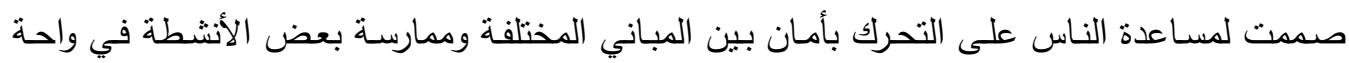
وسط التكتلات المعمارية العالية، وهي قد تكون بنفس الوقت عبارة عن مناطق وأماكن وساحات مفتوحة

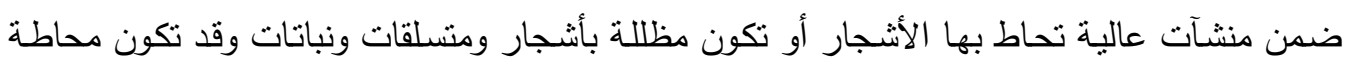

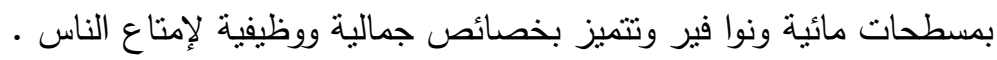

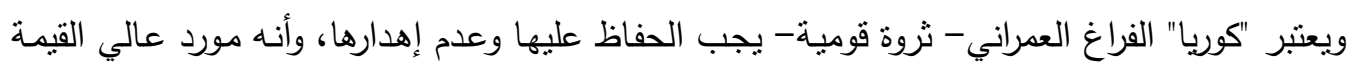
space as a resource

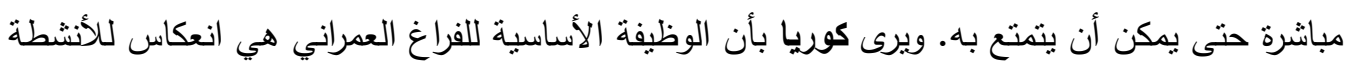

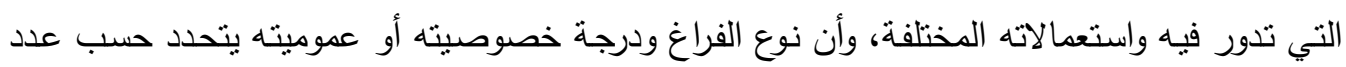
الأفراد المستفيدين منه، كذلك علاقة الجيران يبعضهم سواء كانوا عائلة واحدة أو جيران أو سكان لمنطقة

واحدة [ 5] .

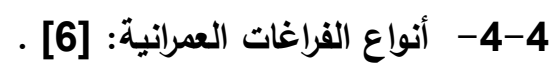
يوجد العديد من أصناف الفراغات تتدرج من حيث المساحة والاستخدام وتتمثل بالساحات المدنية للشوارع والردهـات المشتركة والواحـة العمرانيـة وردهـة العبور والثـارع كسـاحة مدنيـة للمشـاة ومنتزهـات المشـاة المظللة والمكان العام المثالي وأهم هذه الأنواع ما يلي:-

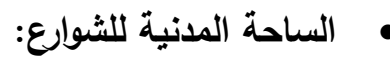

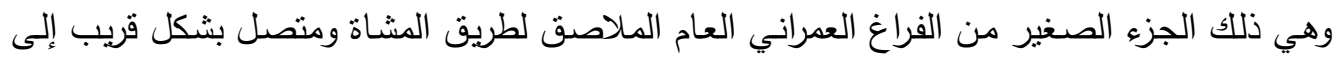
الثنارع العام والساحة تلك تعتبر توسعة لرصيف المشاة. 


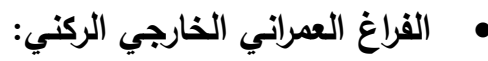

وهي عبارة عن مكان خارجي نشا من تصميم عمارتين متلاصقتنين كجزء من ركن عند التقاء شارعين

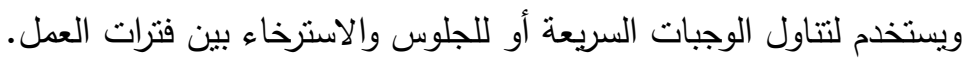

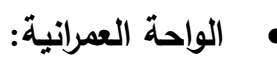

تعتبر نوع من أنواع الساحات العمرانية التي انبتقت فكرتها من جلب الطبيعة إلى قلب المدن المكتظة

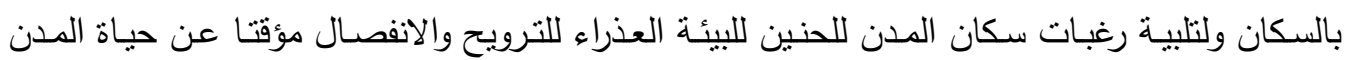
وصخبها، ومن ناحية أخرى فهي تعتبر إعادة توازن للنسيج العمراني والذي بدأت تقل فيه المساحات

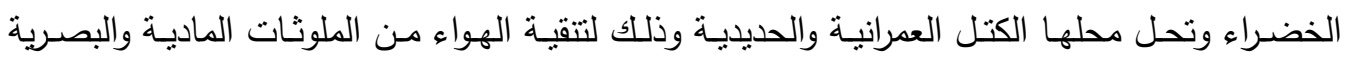

والسمعية للمدن.

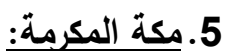

هي مدينة سعودية لها عدة أسماء من بينها أم القرى والحرم والبلد الآمن والبلد الأمين، أمَّا بكه فهو موضع الكعبة داخل المسجد الحرام. وفي مكة المكرمة أقدس مكان للمسلمين- الكعبة ( بيت اله الحرام)

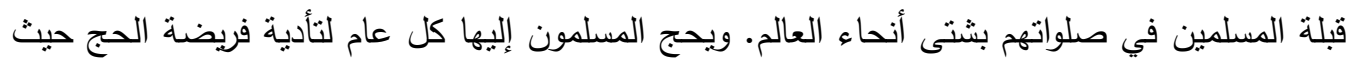

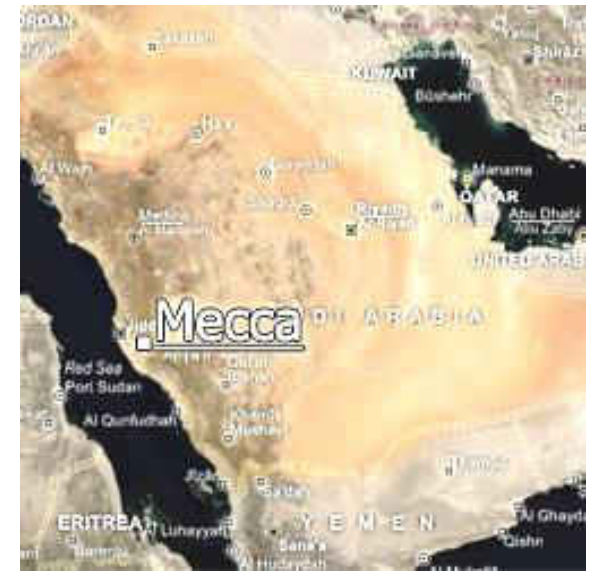
يفد إليها أكثر من مليوني شخص من كل إنحاء العالم، التأدية المناسك.

وهي مدينة مقدسة منذ أيام إبراهيم عليه السلام وفي أيام الجاهلية والإسلام. ومهبط الوحي ومبعث الرسالة الإلهية إئه

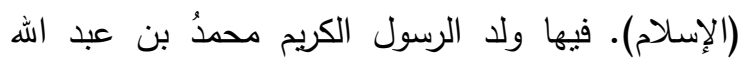

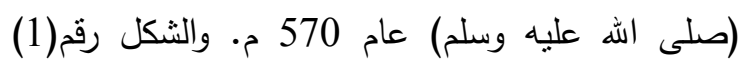

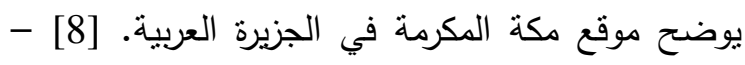

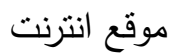

شكل (1)- موقع مكه المكرمة في الجزيرة العربية

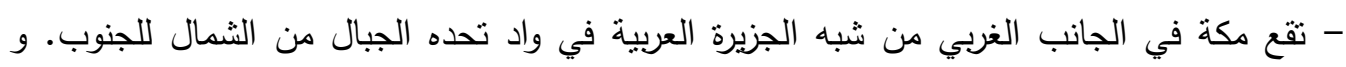

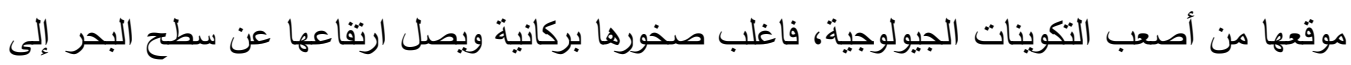
أكثر من 300 منز • ويحدها وادي إبراهيم المنحصر بين سلسلتي جبال جهة الثرق والغرب والجنوب. فالسلسلة الثمالية من الجبال تتألف من جبل الفلق وجبل قعيقعان والسلسلة الجنوبية تتألف من جبل أبي 
حديده غربا، وجبل كدي باتجاه الجنوب الشرقي وجبل أبي قبيس في الجنوب الثرقي وبعده جبل خدمة.

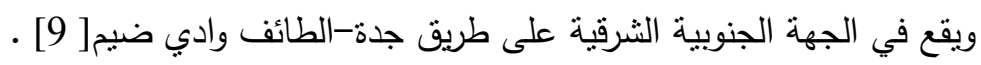

5-1- المخطط الهيكلي المحدث لمكة المكرمة حتى عام 1450هـ-[ 10-بحث عبر google ]. نظراً لمكانة مكة المكرمة المتميزة لما لها من خصوصية دينية وطبيعية واقتصادية واجتماعية وعمرانية

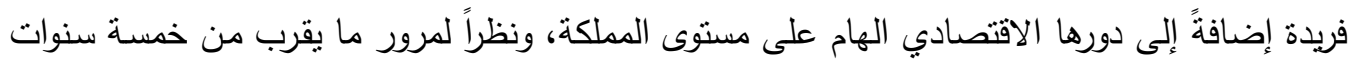

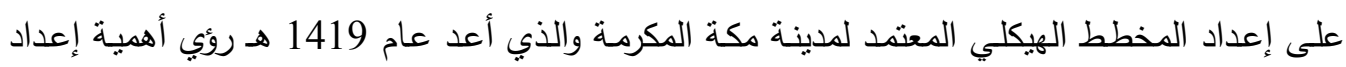
تحديث للمخطط الهيكلي المعتمد لمدينة مكة المكرمسة حتى عام 1450 هـ ليضـع الخطوط العريضـة للتتمية المستقبلية للعاصمة المقدسة بكافة جوانبها وليتوافق مع المتغيرات والظروف الحالية والمسنقبلية. وتقوم الأفكار الأساسية لتحديث المخطط الهيكلي للمدينة علي أساس الواقعية والمرونة في فهم وتقدير

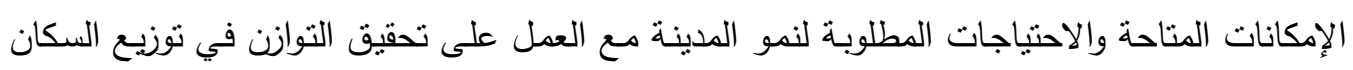

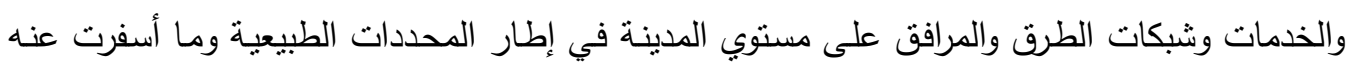

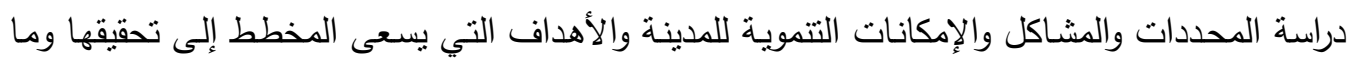
تتاولته الإستراتيجية العمرانية الوطنية والإستراتيجية العمرانية للمنطقة، وقد تم في إعداد هذا المخطط الأخذ في الاعتبار عدد من موجهات التتمية ومنها على النحو التالي: التأكيد على أن المسجد الحرام وما يؤدى فيه من شعائر هو الركيزة الأساسية لتخطبط المنطقة

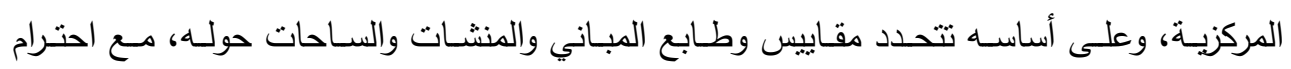

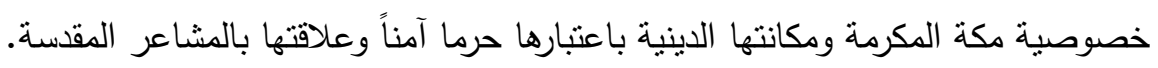
مراعاة خصوصية الطبيعة الطبوغرافية للمنطقة والتكامل معها. احترام النسيج العمراني القائم والمميز لقلب المدينة الأصيل والتكامل معه باعتباره تراثاً إنسانباً مثلها في ذلك مثل المراكز القديمة للمدن العالمية. تخصيص المنـاطق حـول الحرم الثـريف وحتى الدائري الأول لحركـة المشــاة وخاليـة مـن حركـة

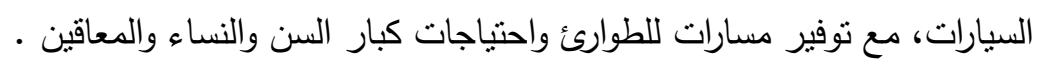

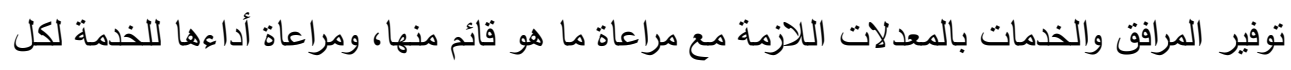
من السكان الدائمين والموسميين.

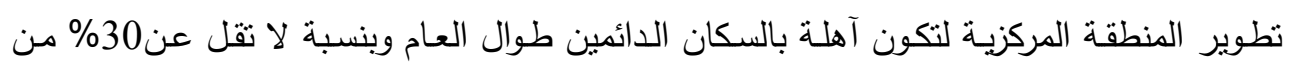
استيعابها الكلى مع توفير الخدمات اللازمة لهم، ويمكن استغلال هذه المساكن أو أجزاء منها خلادل المواسم لتسكين الحجاج والمعتمرين. 
التأكيد على شمولية التتاول التخطيطي لنطوير المنطقة المركزية آخذاً في الاعنبار كافة مشروعات

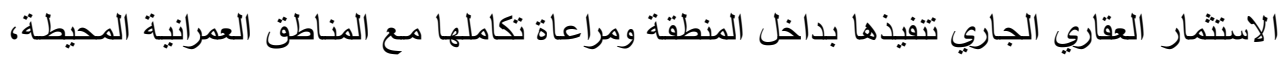
والتصور المستقبلي لمكة المكرمة بصفة عامة.

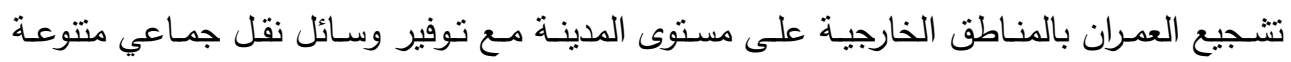

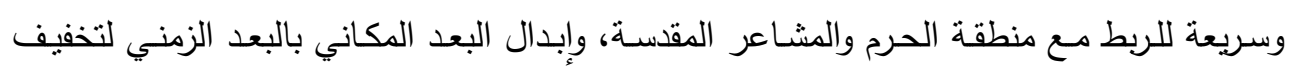
الضغوط العمرانية عن المنطقة المركزية. وعلى ضوء ما جاء في المخطط الهيكلي فقد خلص إلى تحديد عدد من القرارات الأساسية التي تم

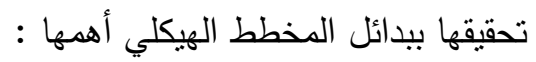
تأكيد المنطقة المركزية وتكثيف الأنشطة الخدمية بها وخلخلتها وإيجاد ضواحي بالمناطق المنبسطة

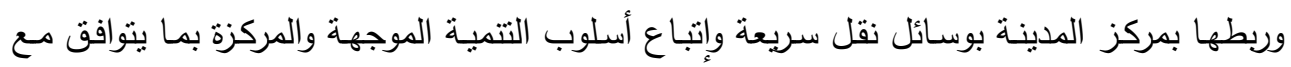
الطبيعة الطبوغرافية ويرفع من الكفاءة الاقتصادية للخدمات وشبكات البنية الأساسية .

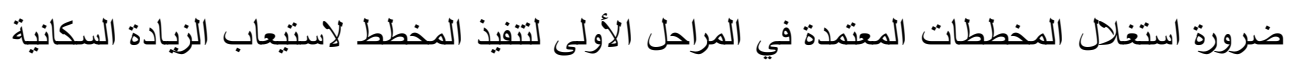

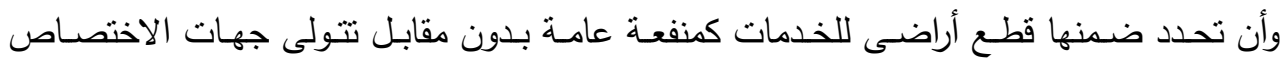

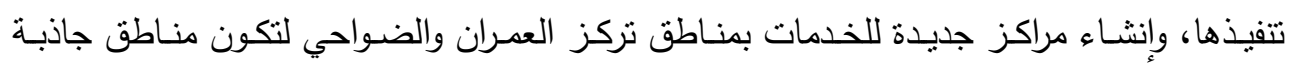
ومتكاملة ذاتيا. تطوير واستغلال سفوح الجبال القابلة للنطوير بمنطقة مني كمناطق للإيواء بما يلائم البيئة وبحلول

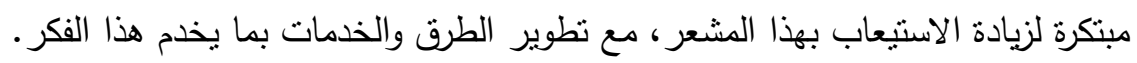

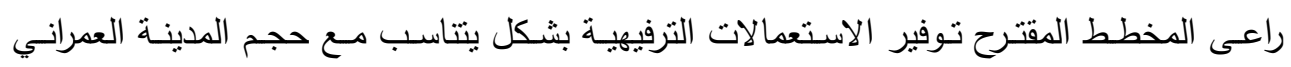
والسكاني لهذا تم اقتراح ثلات منتزهات كبيرة الحجم لتصل مساحة المناطق الترفيهية 4000 هكتار

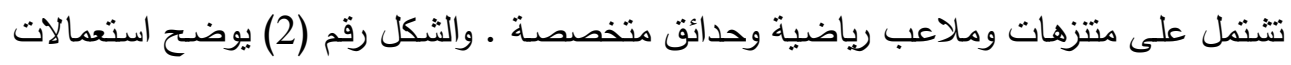
الأراضي بمكة المكرمة حتى 1424هـ، والثكل رقم (2) يبين المخطط الهيكلي المحدث لهنطقة مكة

$$
\text { المكرمة حتى عام } 1450 \text { هـ. }
$$

يدعو الدخطط الإدارات المختلفة الاعتماد على استخدام التقنيات الحديثة وتطوراتها في توفير المرافق والخدمات بطرق أقل تكلفة وعدم الالتزام بالحلول النمطية المكلفة وإيجاد بدائل هندسية وتقنية مبتكرة أكثر انتقائية وأفضل جودة وجدوى. كما تم بالمخطط الهيكلي المحدث لمكة المكرمة تحديد خمس مراحل زمنية للنطوير أخذت في اعنبارها أولويات التتمية العمرانية بالمدينة وعلاقتها بالخطط النتموية للاولة. 


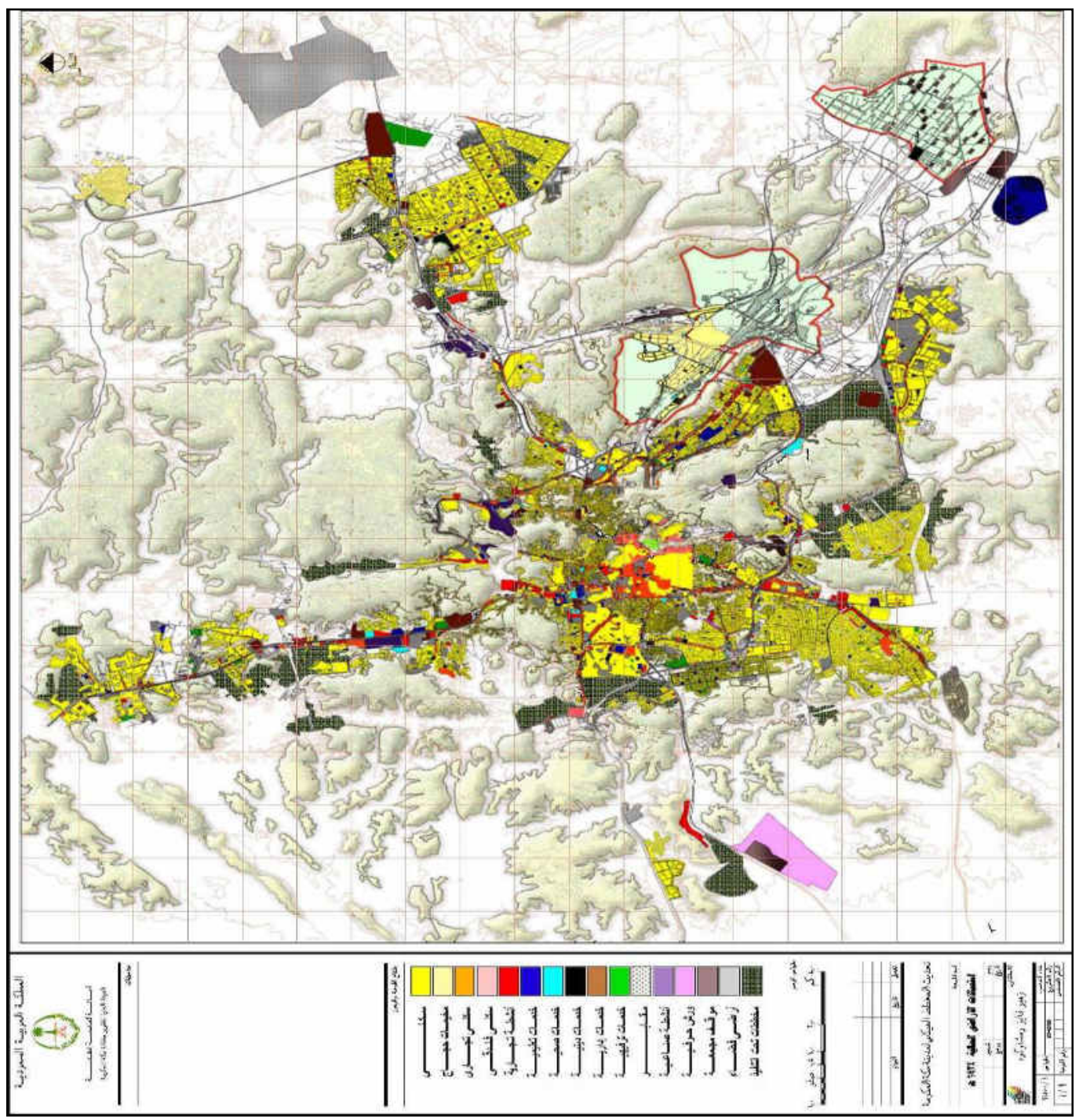

شكل (2)- استعمالات الأراضي بمكة المكرمة حتى عام (1425هـ) -بحث google 


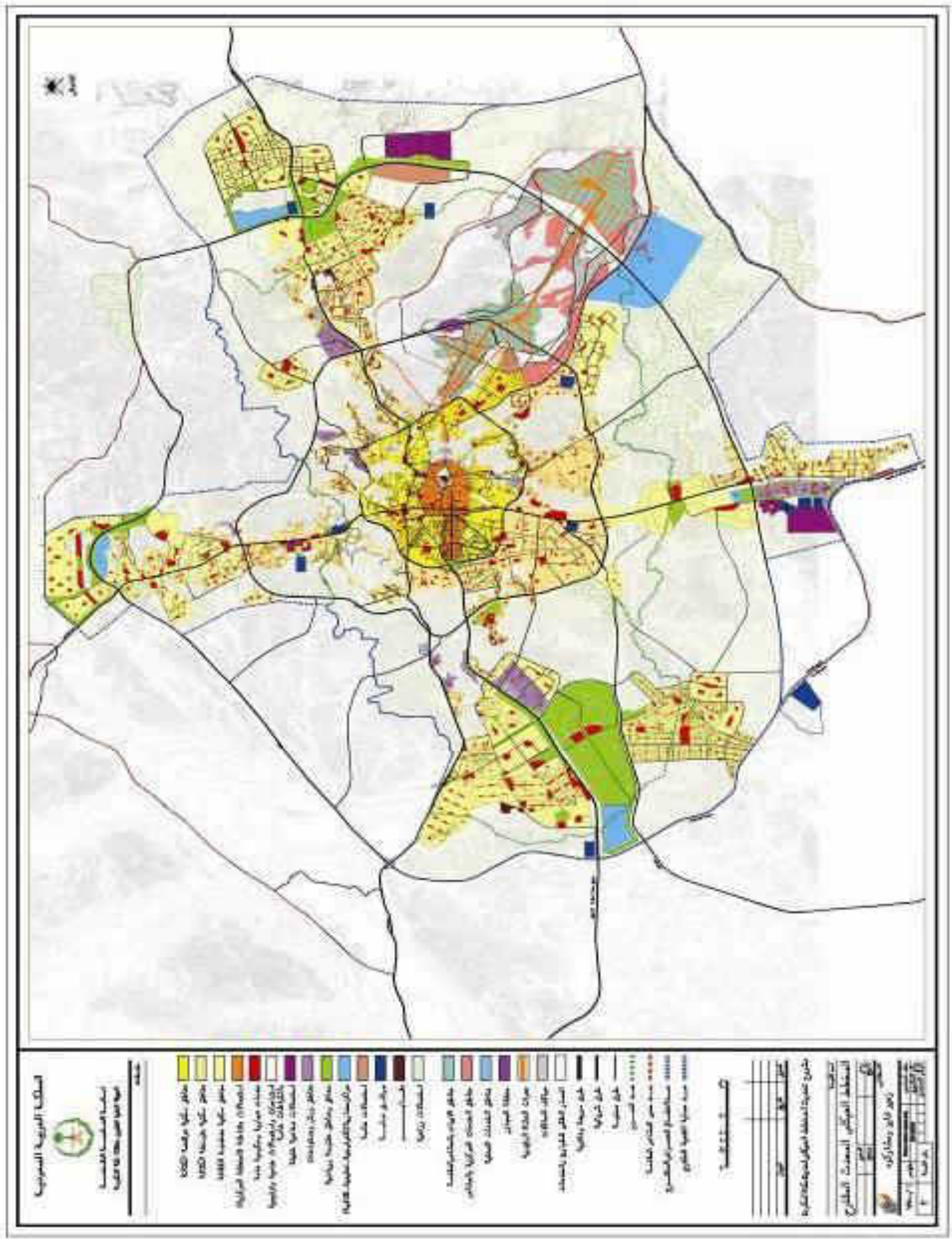

شكل (3)- المخطط الهيكلي المحدث لمكة المكرمة حتى عام (1450هـ)- بحث google 
إن كل من ينظر إلى طبيعة وجغرافية مكة المكرمة ومناخها يجدها بيئة مميزة لا يشاركها فيها مكان أخر

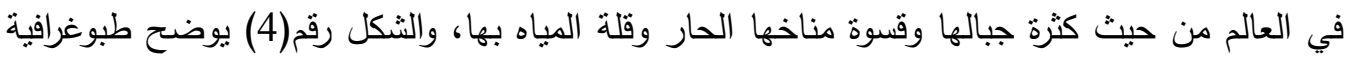

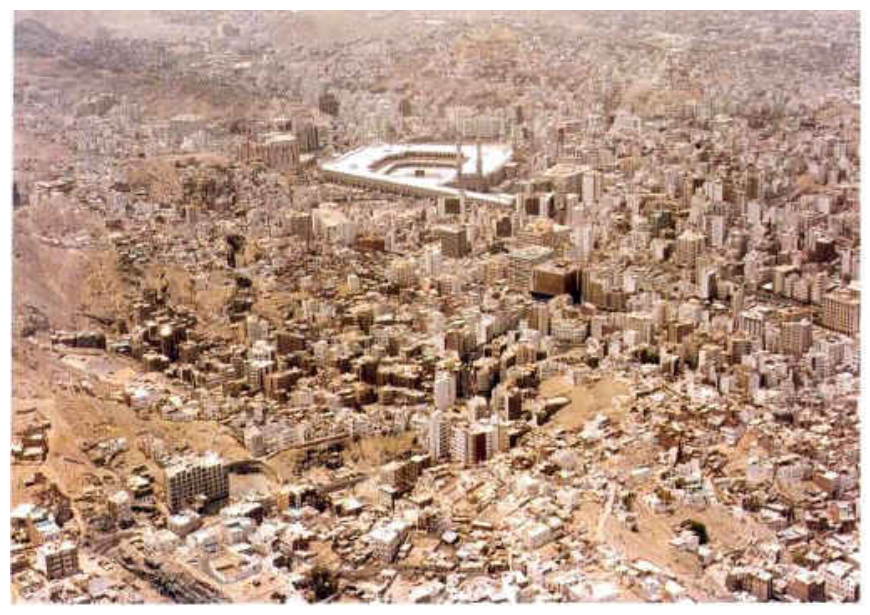

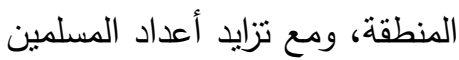

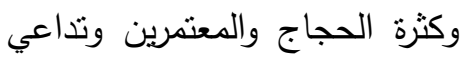
كثير من المباني بمرور الزمن

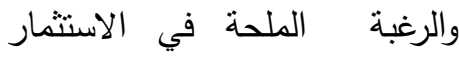

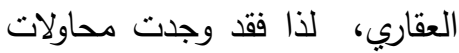
لسد الحاجات جاء معظمها على وجلى عجل ودون دراسة واعية ومتأنية مما ساهم في إيجاد صورة غير لائقة للمنطقة المركزية بمكة لهمية

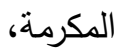

شكل(4) مكة المكرمة وانعدام المسطحات الخضراء في اغلب مناطقها

وحيث أن مكة المكرمة تتميز بان المنطقة حول المسجد الحرام جبلية وعرة ذات تراكيب تضاريسية معقدة في معظم أجزائها وتمثل القطاعات المستوية جزءا بسيطا منها، أدى ذلك إلى استغلال المنطقة الوسطية للمرور الآلي الموصل إلى الحرم ولم يكن هناك مجال لإيجاد متتفسات عامة.

ونتيجة للكنافة البنائية الكبيرة في مكة المكرمة وحول المسجد الحرام وخاصة تلك المباني الراسية التي

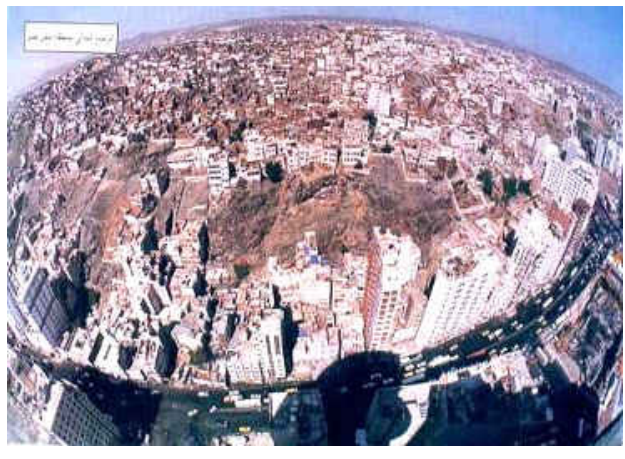

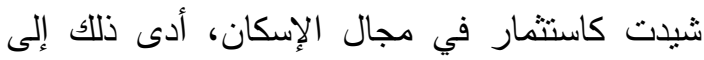

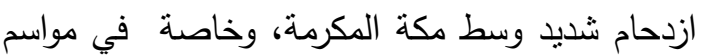
الحج والعمرة، مما يؤثز على شحة الفراغات والمتنفسات داخل مناطق مكة المكرمة إذا ما نظر إلى لى لئل

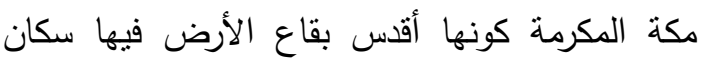
قاطنون مستقرون وذلك واضح من الثكل رقم(5). شكل(5) (כ)

منطقة مكنظة بالمباني السكنية العالية-مكة-جبل عمر

5-2-5 - العمران في مكة المكرمة.

إذا كان تكس السكان يتسبب في حدوث مشاكل خطيرة صحية ونفسية واجتماعية للإنسان بشكل مباشر رفان التكس العمراني يتسبب أيضا في حدوث مشاكل عضوية ونفسية واجتماعية ولكن بشكل 
غير مباشر , وهي لا نقل خطورة عن مشاكل التكدس السكاني ,وخاصة إذا ما نظرنا إلى التكس السكاني الذي تكنظ به منطقة مكة المكرمة, وذللك عندما يهاجر كثثر ممن يكونون تجارة في مكة من مختلف مناطق المملكة والثكل(5) يوضح مناطق الهجرة داخل المملكة. بالإضافة إلى نزاحم

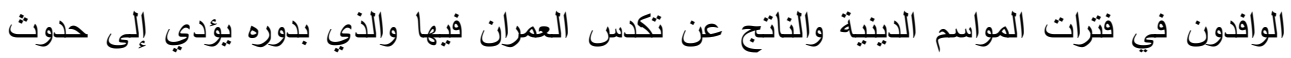
بعض الظواهر المرنبطة به- مما شكل ذلك مشاكل بيئية للكبار والصغار , اختناقات مرورية-انعدام المقياس الإنساني-والتي بدورها تؤثر على حياة الناس سواء الذين يعيشون في هذه المباني العالية

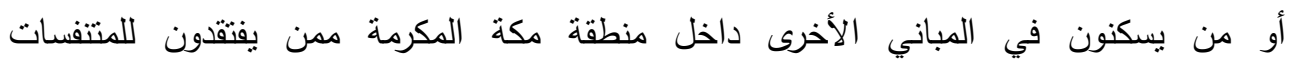

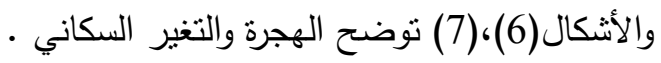

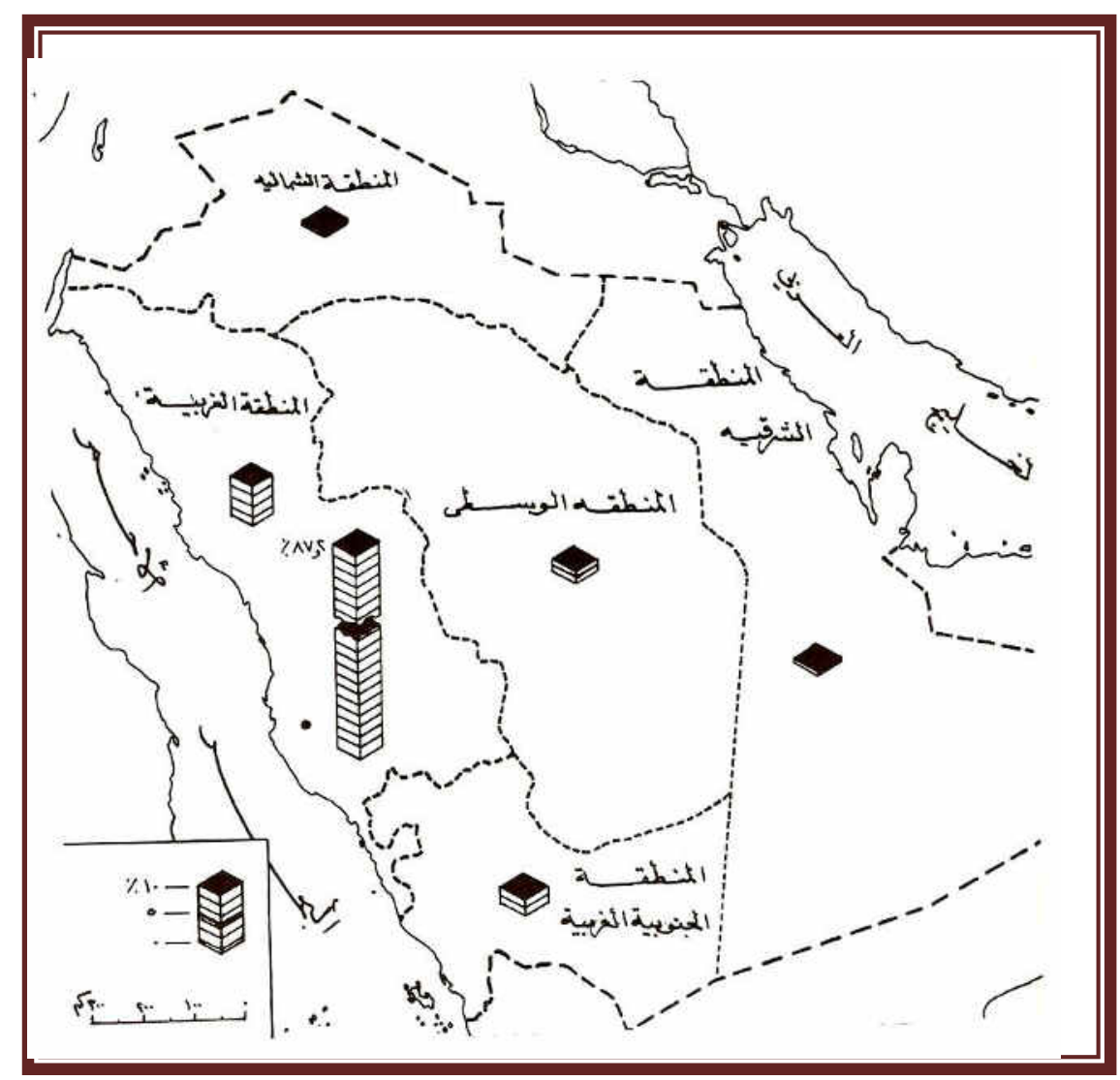

شكل(6) خريطة توضح -الهجره الوافده الى مكة المكرمة-المصدر [12] 


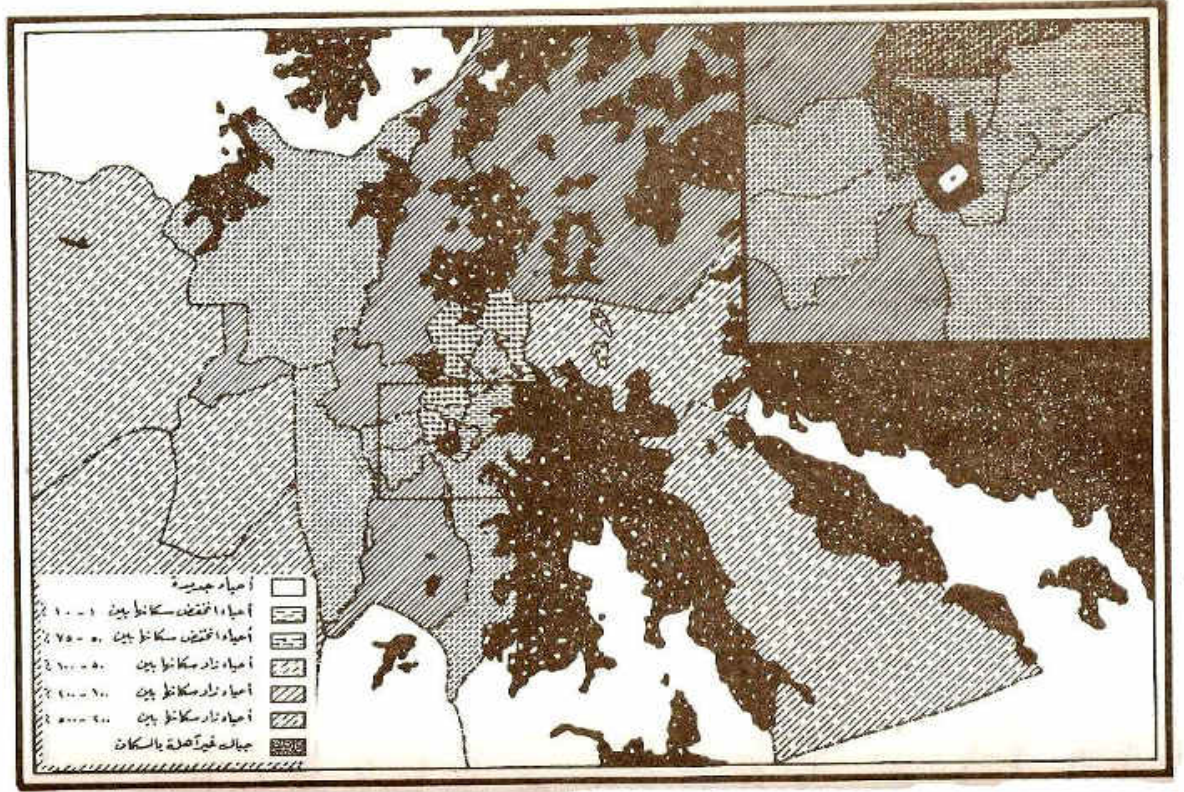

شكل(7) خريطة توضح - التغير السكاني في مكة المكرمة مابين 1291-1402م-المصدر -[12

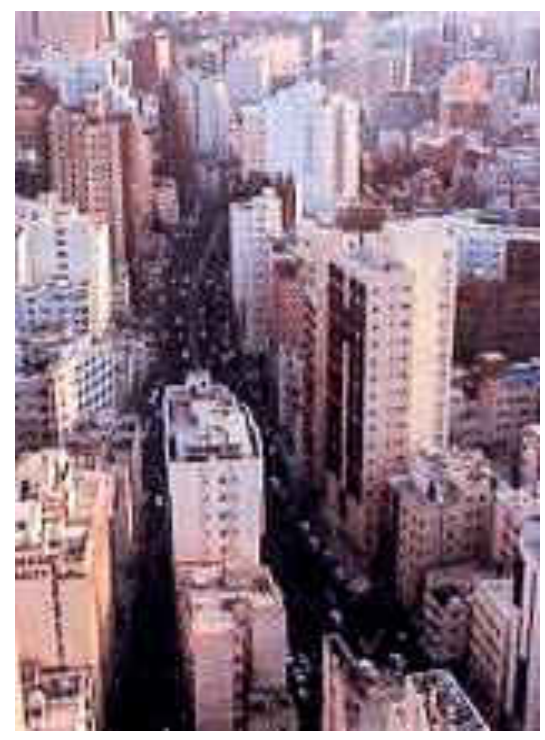

شكل (8) الكثافة البنائية في مكة-والمباني العالية 
ورغم أن العمران الرأسي المخطط له قد نادى به رواد العمارة الحديثة وأشهرهم "لوكوربوزيه" حيث يعتمد

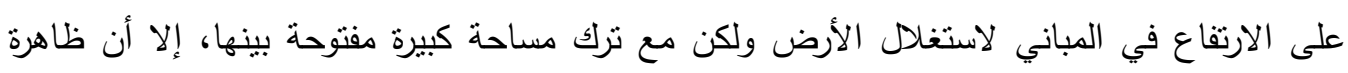

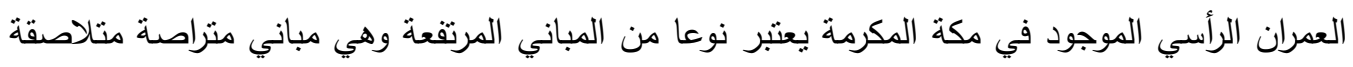
ومكدسة داخل المناطق والأحياء وحول الحرم المكي وذلك لاستغلال الأرض واستثمارها في الإيجارات وخاصة في المواسم الدينية دون عمل أي اعنبارات للفراغات العمرانية التي يجب أن الن تتخلل تلك المباني العالية.

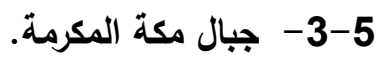

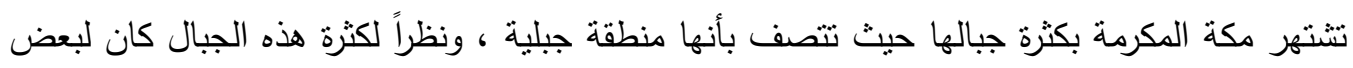

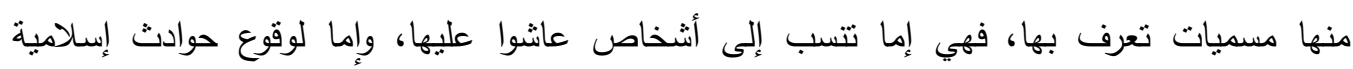

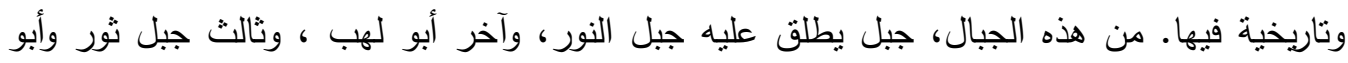

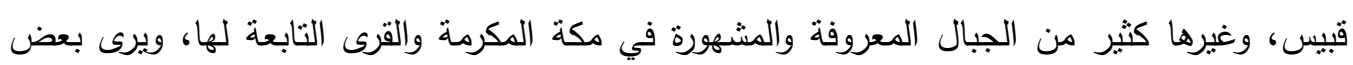
العلماء أن جبل أبو قبيس أفضل جبال مكة المكرمة، لكونه أقرب الجبال للكعبة المشرفة وأول جبل فيل وفئل وضع على وجه الأرض، المصدر رقم[11 - موقع انترنت] ـ ويقع جبل السيدة شمال المسجد الحرام في الحجون وسمي بهذا الاسم نسبة للسيدة خديجة زوجة الرسول صلى الله عليه وسلم ويصل ارتفاعه الأله

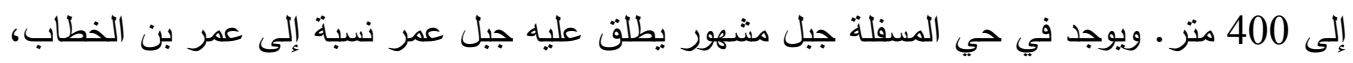
وهو من الجبال المأهولة بالسكان في مكة، حيث يشت ولث الاكتظاظ فيه خاصة في السفوح المواجهة للمسجد. ولكن الآن تم إزالة المباني لعمل مشروع جبل بله عمر [11 - موقع انترنت]

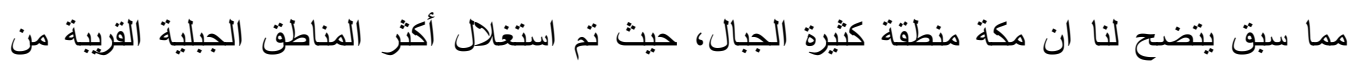

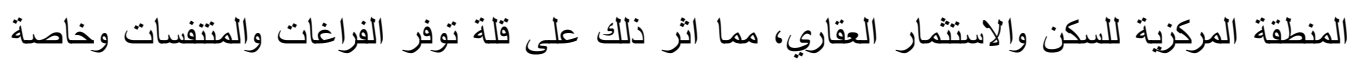
في المناطق القريبة من المنطقة المركزية.

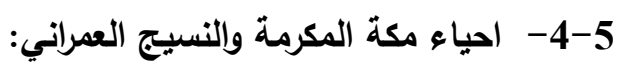

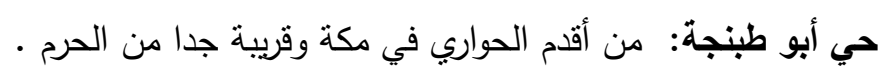

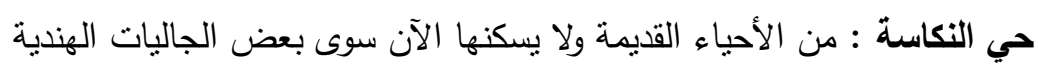

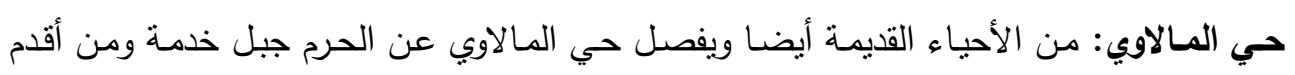
سكانها الحضارمة و بعض القبائل. 


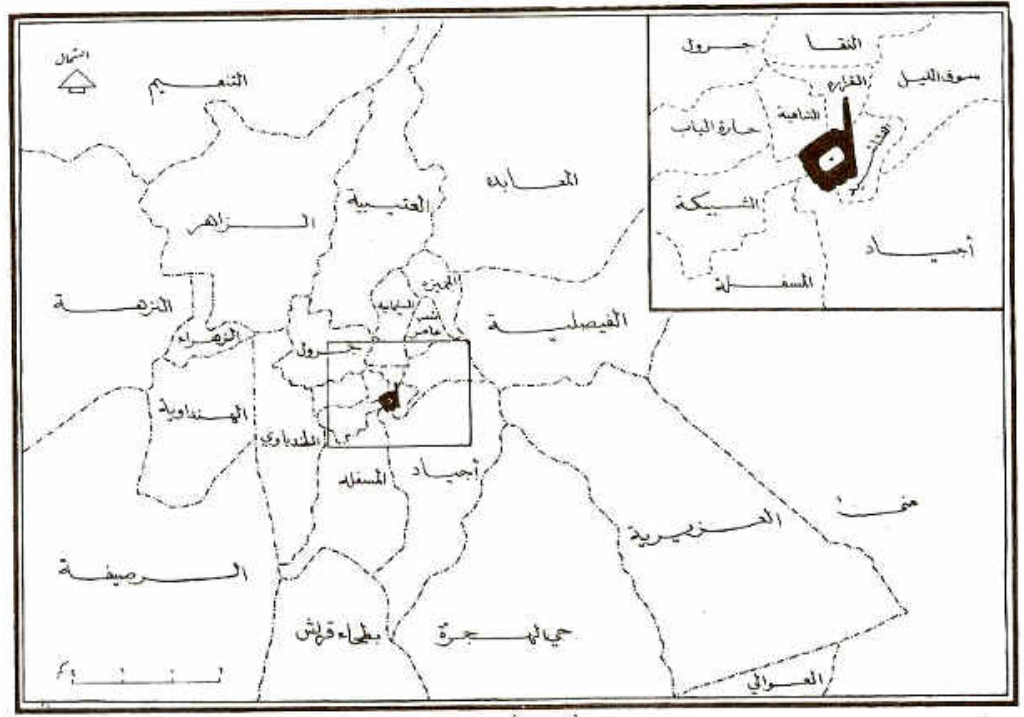

شكل (9) خريطة توضح-أحياء مكة المكرمة وعلاقتها بالمنطقة المركزية-المصدر [12]

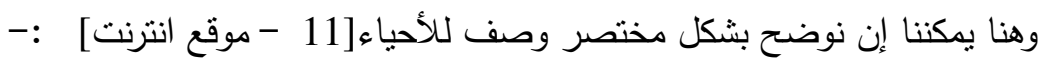

حي التيسير : حي التيسير نموذج للمناطق التقليدية القديمة بمكة المكرمة ويظهر العفوية والتتوع في

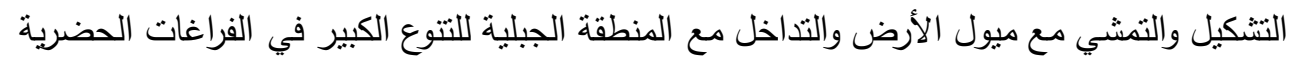
]14]- لتلك المنطقة. حي شارع منصور: من الأحياء القديمة التي تتصف بمنازلها الثعبية ويسكنها الآن عدد كبير من الجاليات الإفريقية به جزء من كلية التربية للبنات والتي تضم فقط قسم الاقتصاد المنزلي

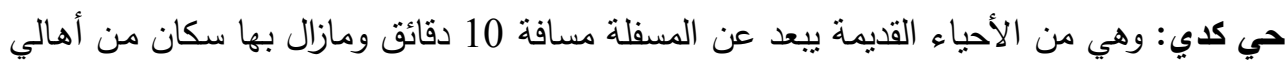
مكة ولكن أغلب سكانها مقيمين. حي الخانسة: تعد من الأحياء الجديدة نوعا ما ولكن يغلب على منازلها الطابع الثعبي.

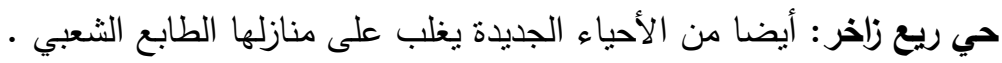

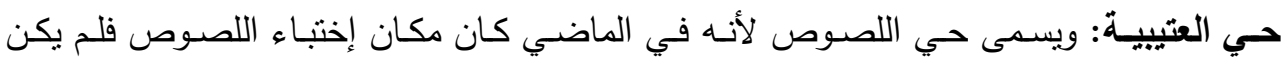
يستطيع أي شخص العيش فيه ولا حتى المرور من شوارعه يثتهر الآن بأسواقه المتتوعة الثعبية

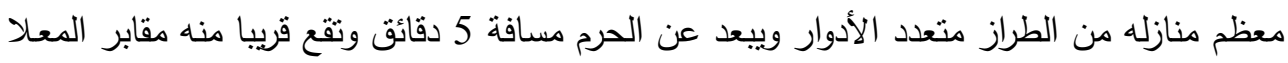

حي الزاهر: يقع قريبا جدا من حي العتيية فمن حي الزاهر يمكن الذهاب مباشرة إلى العتيبية عبر أكثر من طريق مفتوح ويبعد عن الحرم مسافة 15 دقيقة تقريبا. 
حي النزهة: لا يبعد كثبرا عن حي الزاهر ومنه يمكن الوصول إلى شارع يسمى الستين، وحي النزهة من الأحباء المشهورة في مكة المكرمة بكثرة المحلات التجارية.

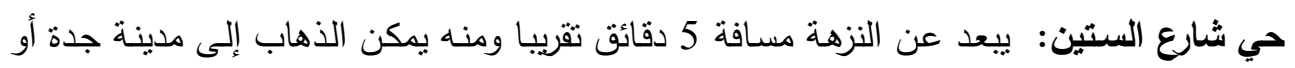
حي الرصيفة أو الذهاب إلى منطقة الحرم المكي ويبعد عن الحرم مسافة 10 دقائق.

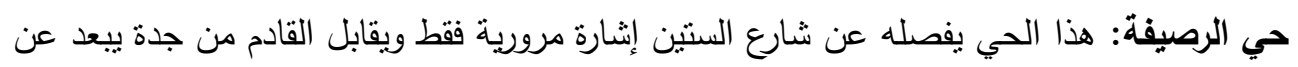
الحرم مسافة 15 دقيقة تقريبا وبه ملاعب وملاهي للأطفال. حي المسفلة: وهو من أقدم أحباء مكة قريب جدا من الحرم المكي به عدد كبير من الفنادق والثقق المفروشة. حي الكعكيـة: مـن الأحياء الجديدة في مكـة المكرمـة فلم يكن معروفـا منذ القدم بـل كان ممرا للمسافرين وقطاع الطرق أمسا اليوم فهو حي سكني بـه العديد من الفلل السكنية والمرافق العامـة والاستراحات .

حي العوالي: أيضا من الأحياء الجديدة في مكة المكرمة يبعد عن الحرم مسافة نصف ساعة .

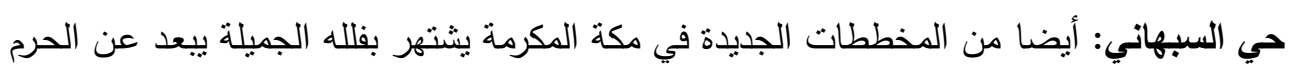

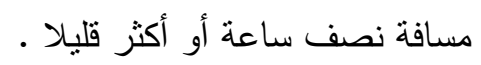
حي العزيزية: أيضا من الأحياء التي لم تكن معروفة من قبل ـاعل -حديث.

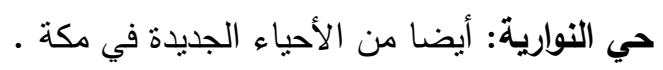

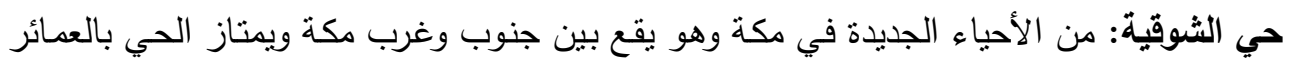
الحديثة.

والثـكل النـالي رقم (10) يوضـح النسيج العمراني لمدينـة مكة المكرمـة وتوزيع المنـاطق السكنية التقليدية والحديثة عليه. بالاضـافة الى شكل (11) صورة جوية لمنطقة مكة المكرمة يغلب عليه الاحياء القديمة التي تقتقد للفراغات.

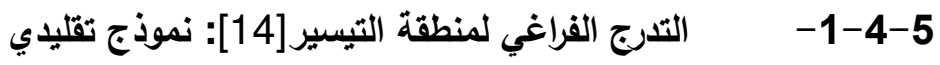

نسبة الفراغات بلغت حوالي ^^ \% من إجمالي مساحة الكتلة العمرانية نوزع الفراغات على ستة مستويات رئيسية .كما بلاحظ من خلال الخريطة أن الفراغات العامة وشبه العامة) القصبات و البرحات والحارات والأزقة (تنكل ب7 \% من إجمالي المساحات المفتوحة بالمنطقة .أما النسبة الباقية ؟r (\% تمثل أحواش وأفنية داخلية وهذا يتلاءم مع احتياجات سكان( المنطقة الوظيفية لأداء أنشطتهم الحياتية في جو من الخصوصية.كما أن شبكة الطرق لها تدرج واضح ويعكس أنثطة السكان اليومية حيث تتضمن تلاك الثبكة قصبتين رئيستين تتمركز عليهما الأنشطة التجارية ويتقرع منهما حارات وأزقة وتنتهي بأزقة مقفلة. 


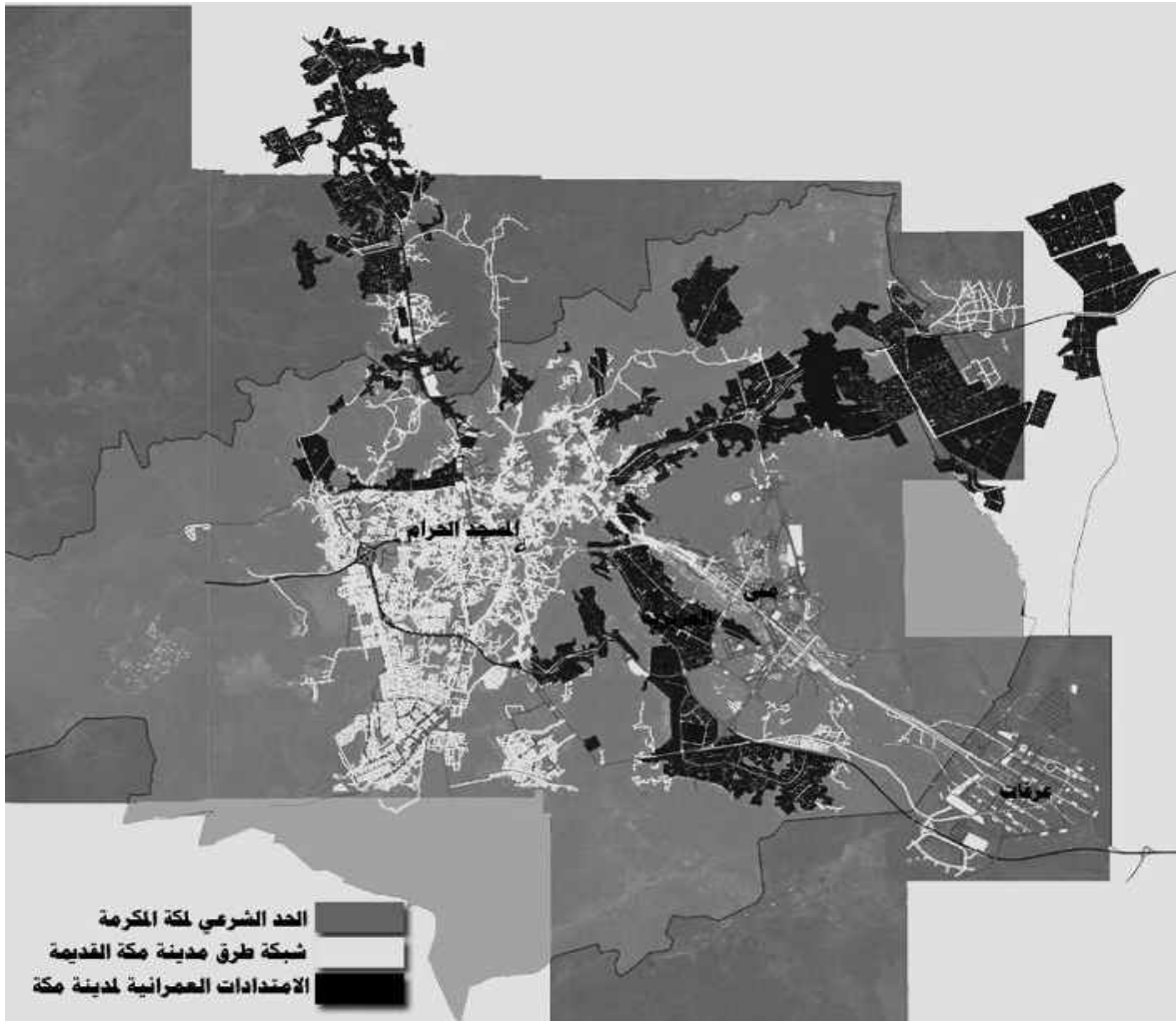

شكل (10) يوضح النسيج العمراني لمدينة مكة المكرمة والامتدادات العمرانية فيها.المصدر [14]

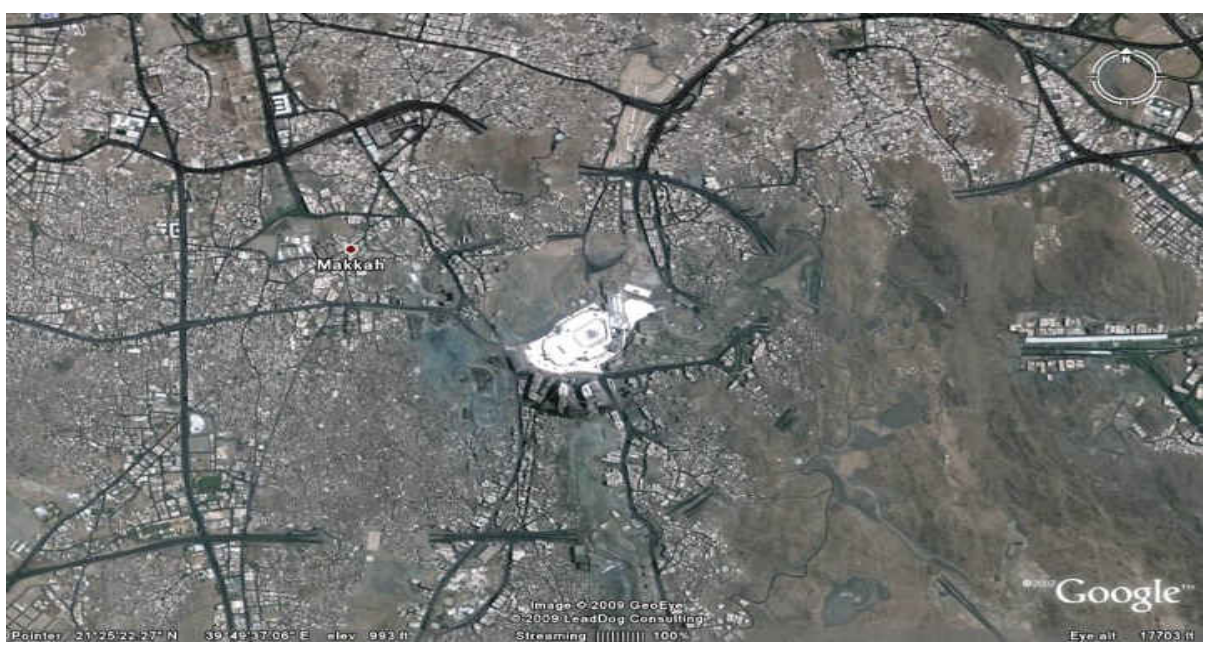

شكل (11) صورة جوية لمنطقة مكة المكرمة موضحا يغلب عليه الاحياء القديمة التي تقتقد

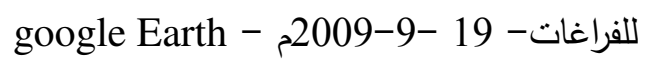




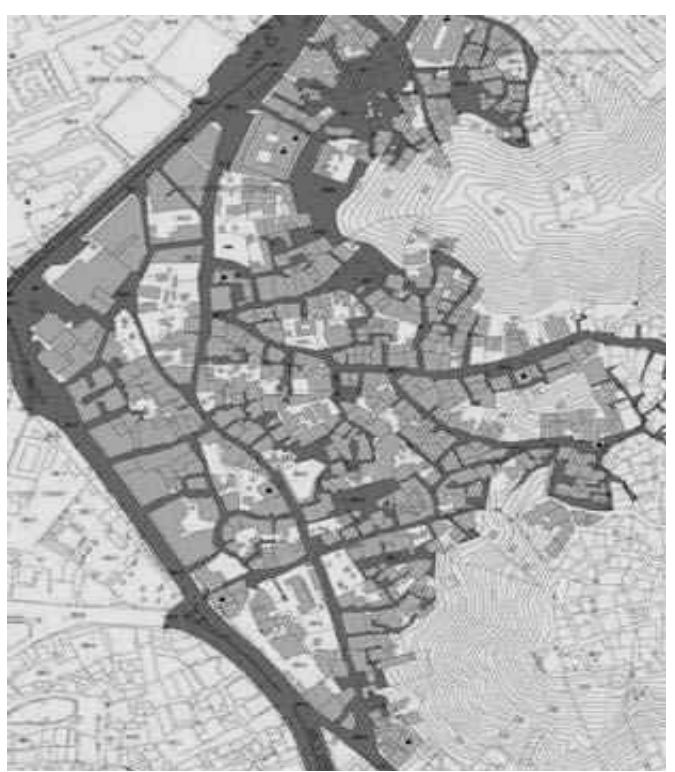

شكل (12) النسيج العمراني لمنطقة التيسير في مكة المكرمة مبينا عليه الكثافة العمرانية[14]- المصدر
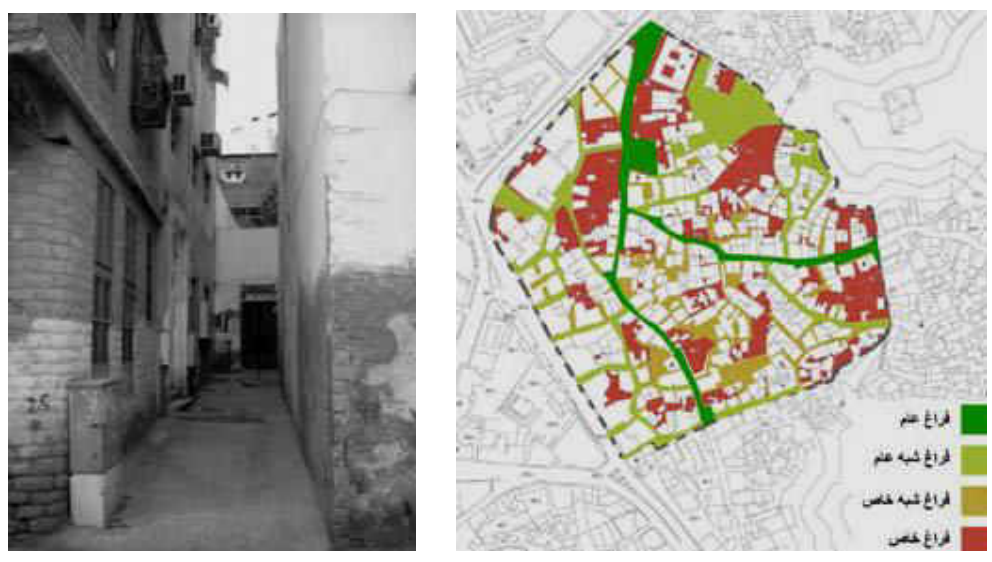

شكل (13) يوضتح التدرج الفراغي لمنطقة التيسير في مكة المكرمة - نهايات مقفلة لنفس المنطقة[14]- المصدر

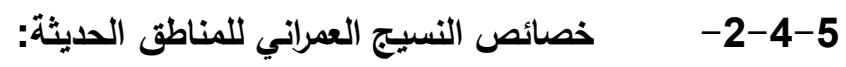

يعتمد التخطيط في كافة المخططات الاتجاه الثبكي بما يعطيه من وضوح وبساطه في التعرف على ملامح المنطقة. والثكل رقم (13) يبين صورة جوية للاحياء القيمة لمنطقة مكة المكرمة، والاشكال (14)و (15) يعرض عدد (2) نماذج بمدينة مكة المكرمة هي (مخطط ستر اللحياني -مخطط الإسكان) على الترتيب، موقعا على كل منها شبكة الطرق ويظهر عليها النمط الشطرنجي.. 


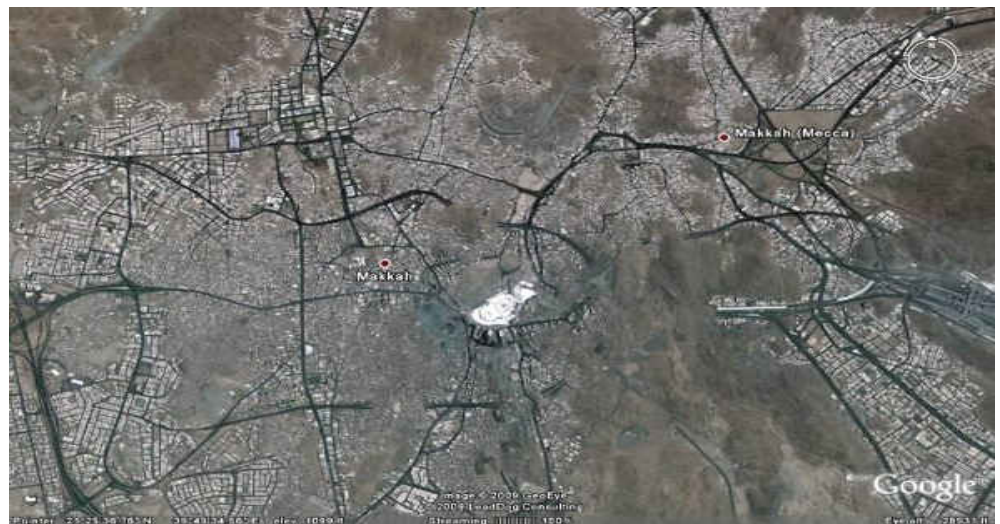

شكل (14) صورة جوية لمنطقة مكة المكرمة موضحا فيها الاحياء الجديدة-على اطراف منطقة مكة المكرمة google Earth - 2009-9- 19 -
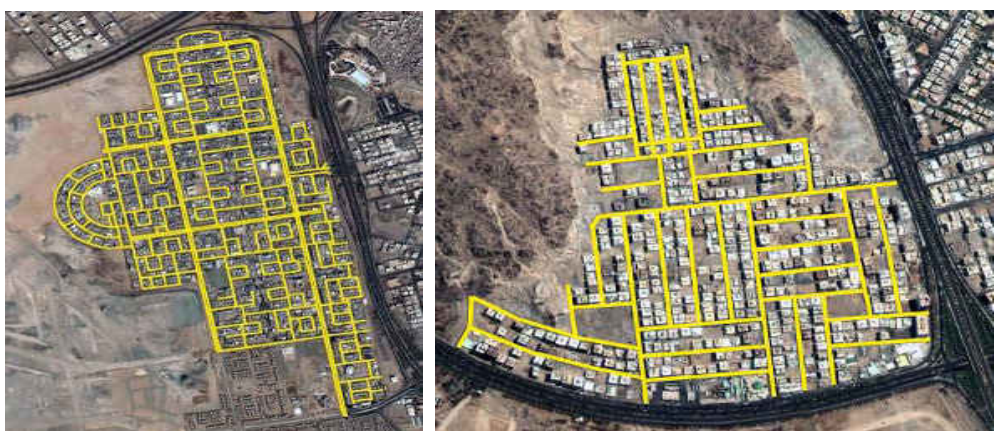

شكل (15) يوضح مناطق حديثة في مكة المكرمة ذات تخطيط شبكي-مناطق(ستر اللحياني-

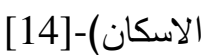

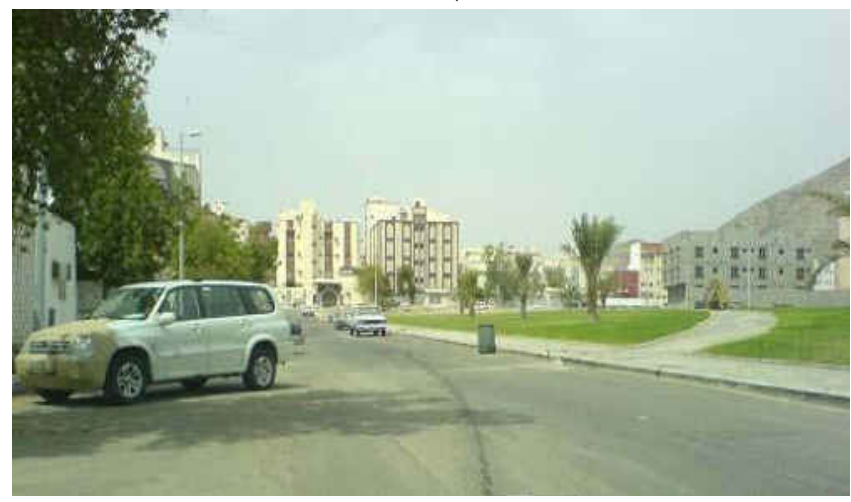

شكل (16) نموذج للفراغات العامة والمساحات المفتوحة 
ومن خـلال الأشكال السابقة يتضـح لنـا أن الأحياء القديمة لمكة المكرمـة لم تكن تراعي الفراغات

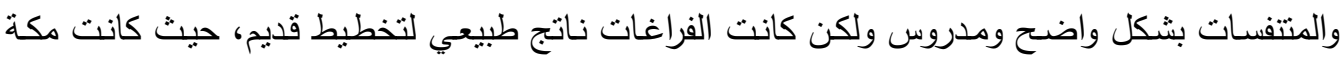
الركرمة نتيجة للزيارات الموسمية فيها فقد كان السكان يفكرون كيف يوجدون محلات للتجارة. والثكل

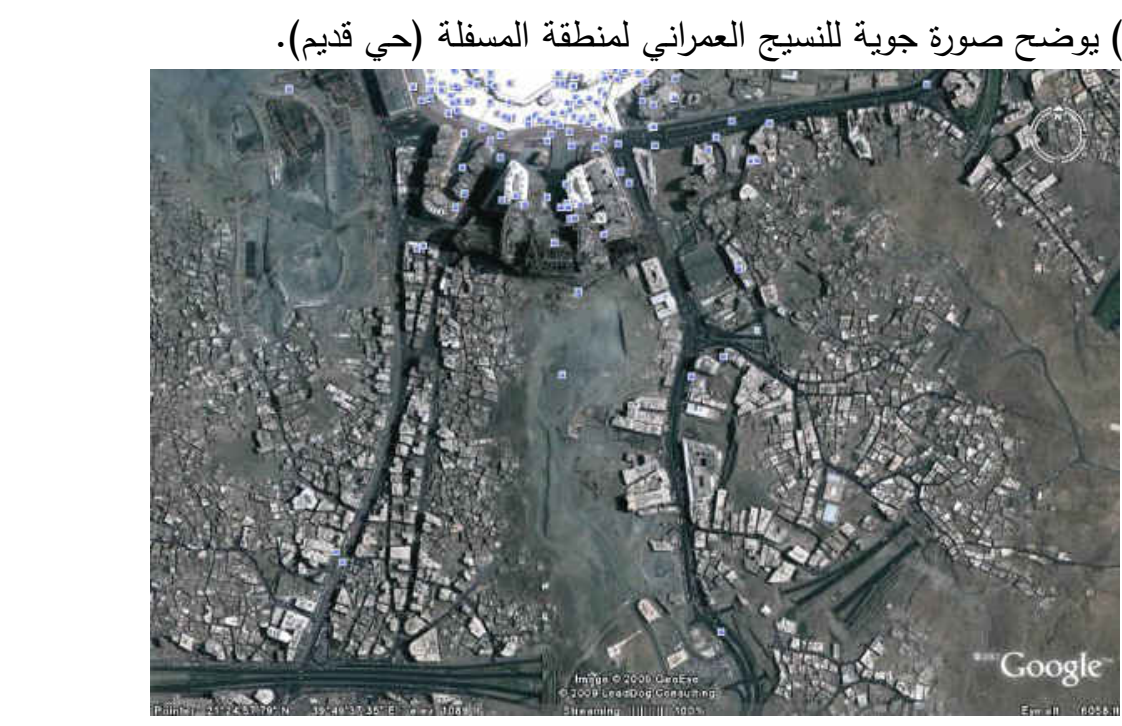

شكل (17) النسيج العمراني لحي المسفلة (قديم)-صورة جوية-ماخوذة بتاريخ 19-9-2009م google Earth

أما بالنسبة للأحياء الجديدة فقد حاولت الجهات الرسمية إيجاد بعض المتتفسات ولكن مازالت بعيدة عن سكان وسط المنطقة المركزية- مشكلة الدراسة. والأشكال (18)، (19) تبين التخطيط الحديث لهنطقة

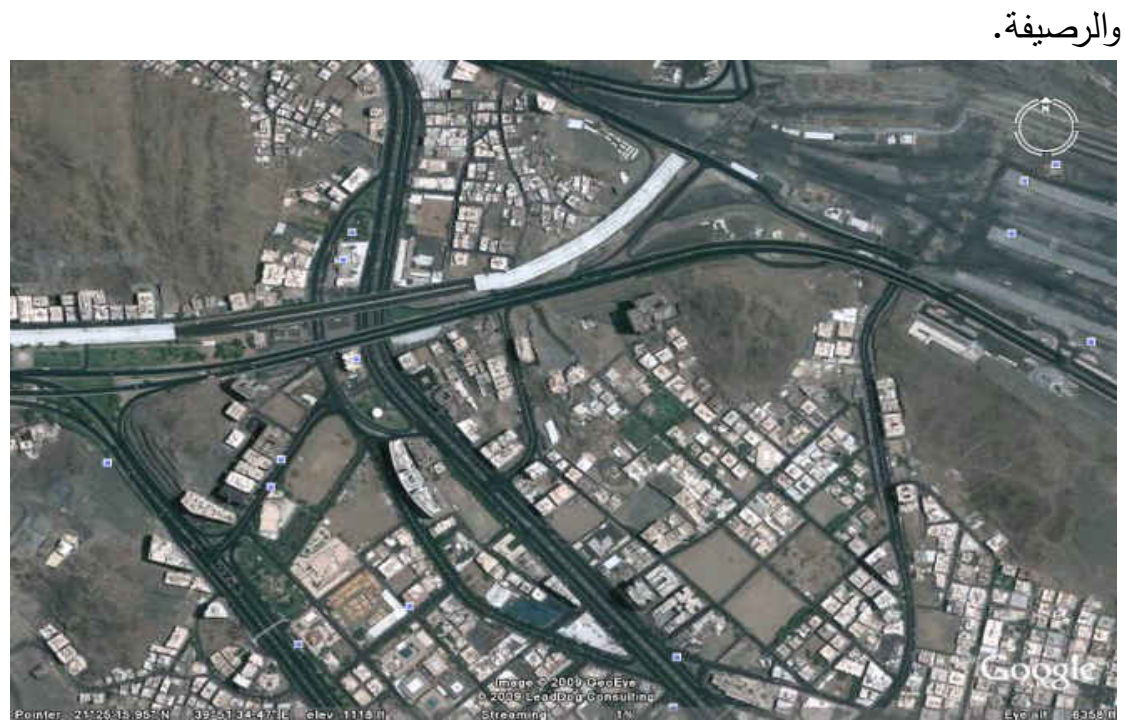

google Earth - شكل (18) حي العزيزية (حديث)- صورة جوية ماخوذه بتاريخ 19-9-2009م 


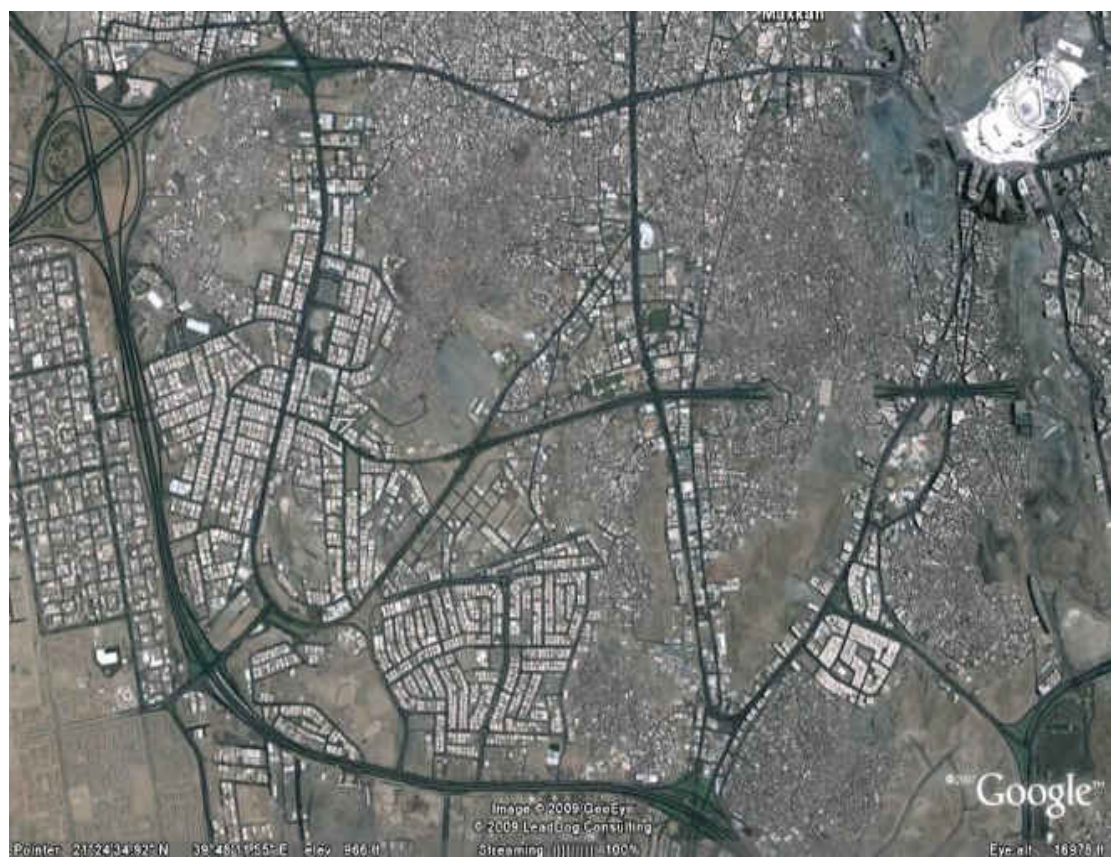

Google Earth - شكل (19) حي الرصيفه (حديث)- صورة جوية- ماخوذه بتاريخ 19-9-2009م 5-5- - الفراغات العمرانية في مكة المكرمة.

تعتبر الفراغات المفتوحة والتي تحتوي على المسطحات الخضراء والساحات-المتتفسات- من أهم الفراغات العمرانيـة التي يجب أن يكون لها أهمية في تتميـة المناطق السكنية أو العمرانية بشكل

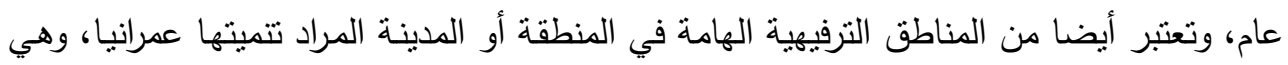

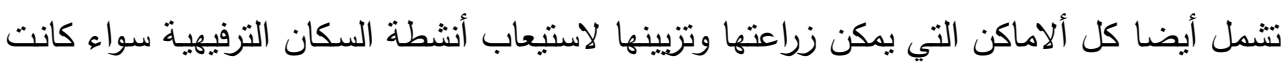

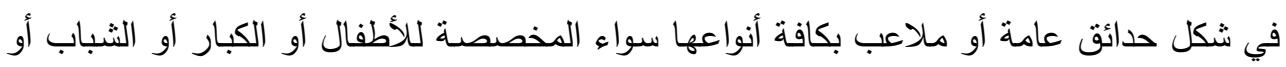

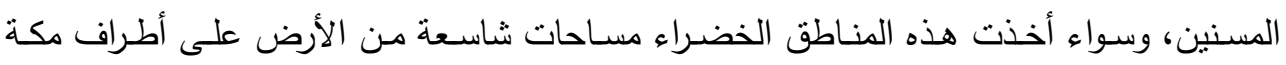

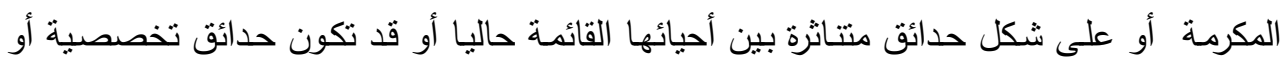
شريط اخضر يفصل بين استعمالين غير متجانسين من استعمالات الأراضي. 
الجدول التالي يوضح استعمالات الأرض (الحدائق) في مكة المكرمة سابقا كما في المخططات:-[13]

\begin{tabular}{|c|c|c|}
\hline النسبة المئوية & المساحة بالهكتار & استعمالات الارض \\
\hline 60.3 & 6019 & الاسكان \\
\hline 30.2 & 3014 & شبكة الطرق \\
\hline 0.4 & 40 & المساجد \\
\hline 2.4 & 240 & المدارس \\
\hline 2.8 & 280 & الحدائق \\
\hline 0.9 & 91 & مواقف السيارات \\
\hline 1.8 & 180 & الأنشطة التجارية \\
\hline 1.2 & 120 & استعمالات أخرى \\
\hline$\% 100$ & 9984 & \\
\hline
\end{tabular}

الجدول السابق يبين ان نسبة الحدائق 2.8 وهي نسبة ضئيلة لما تحتاج إليه مكة المكرمة في فترة

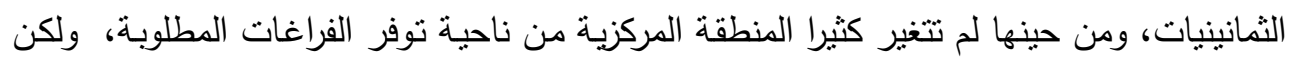

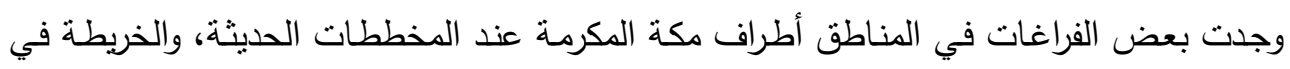

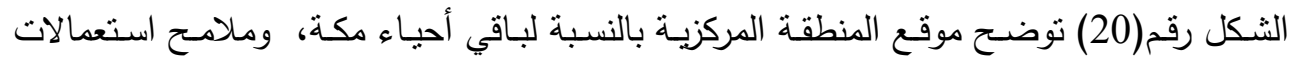

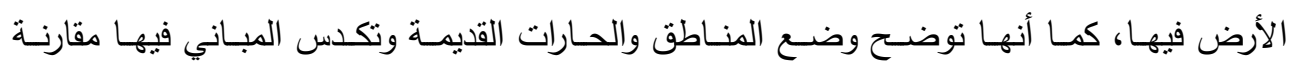
بالتوسعات الحديثة أطراف المنطقة المركزية. 


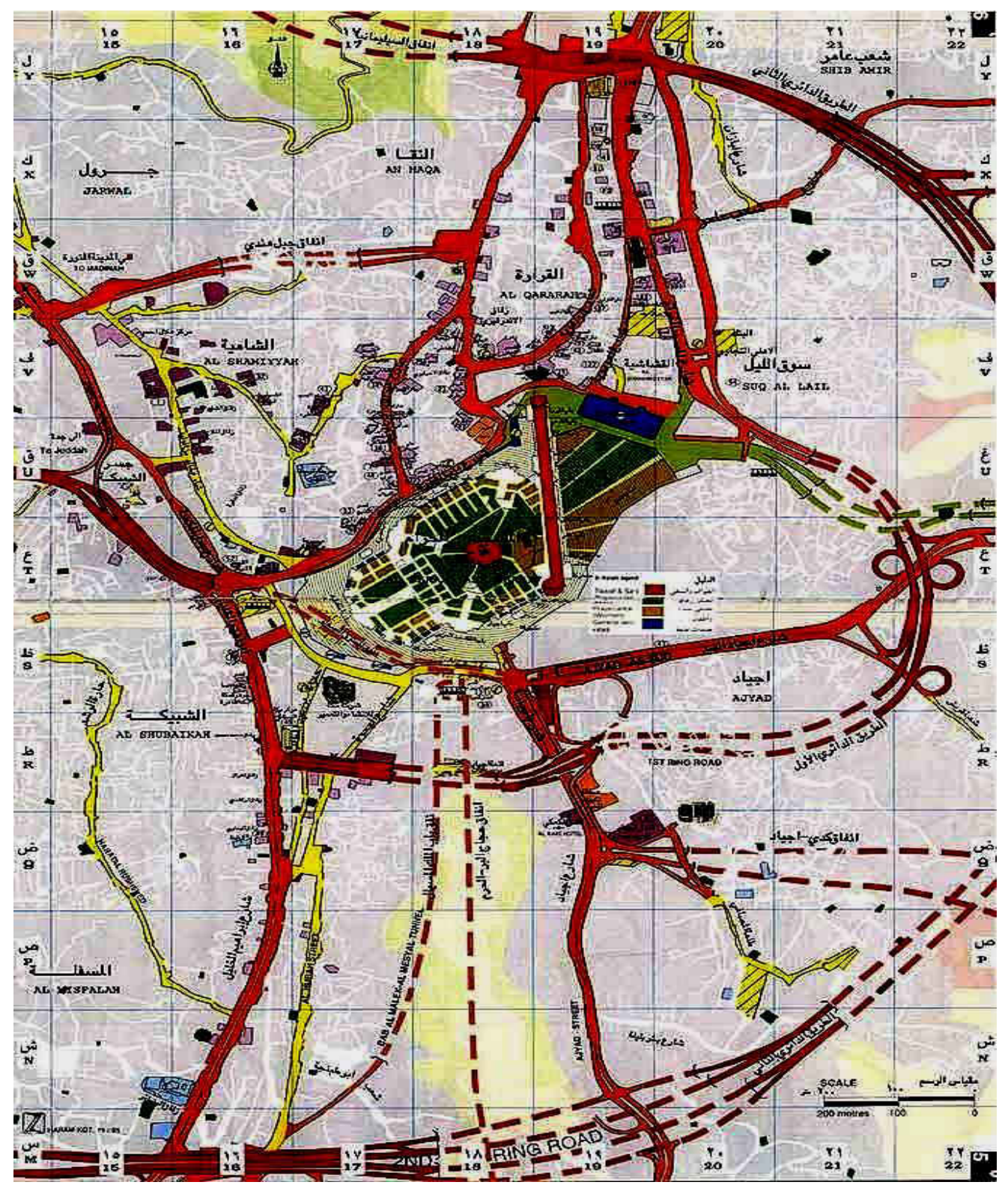

شكل رقم(20) يوضح وضع المناطق والأحياء وتكدس المباني في الأحباء التي تقع حول المنطقة المركزية

كما يبين الثنكل رقم (21) بعض ملامسح النمط العمراني لمكة المكرمـة والذي يتميز بتكثيف البنـاء والارتفاع رأسيا وذلك لصعوبة البناء على المنحدرات الجبلية وانحصار البناء في الأودية والثعاب بينهما

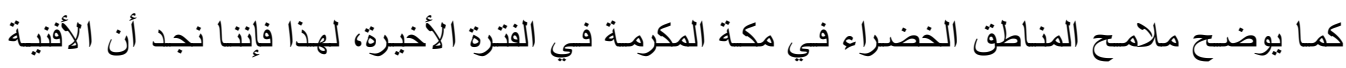

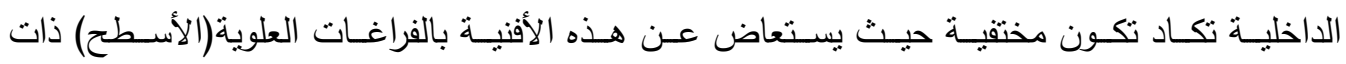


الأسـوار (الدراوي) العاليـة المخرمسة لتوفير الخصوصية لمستخذمي هذه الأمساكن في الأعمـال داخل

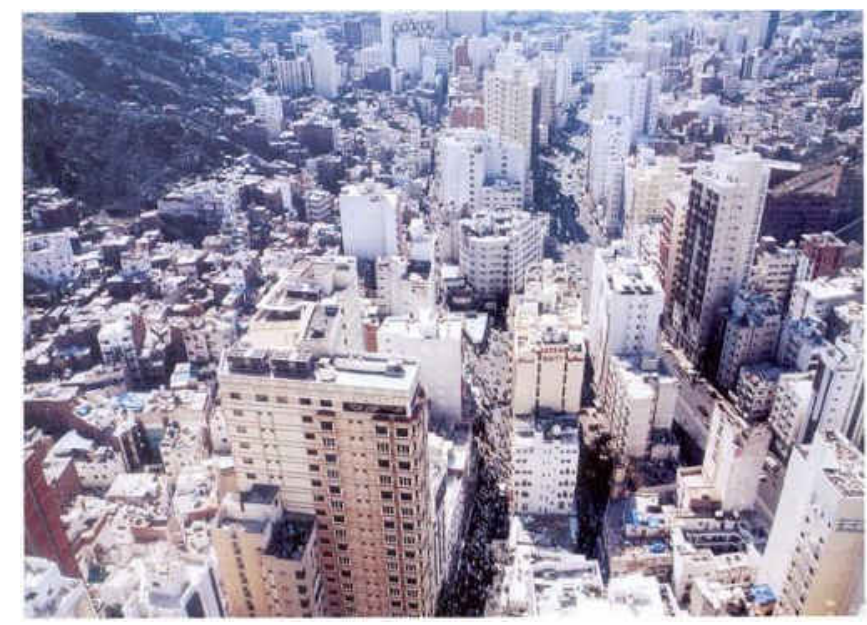

شكل (21) المباني العالية في مكة والجبال المحيطة وقلة المتنفسات العامة

وعندما نتعرض للفراغات العمرانية نجد أن المناطق الخضراء وتوزيعها ونسبها من العمليات الحيوية في تخطيط الددن والأقاليم لذلك يجب الاهتمام بها من قبل الجهات المختصة. لذا فإن المسطحات الخضراء تلعب دورا بارزا بالنسبة لحياة البشر من جهة وبالنسبة للتوازن الايكولوجي من جهة أخرى فأهمية المسطحات الخضراء تتبع من ضرورتين أساسيتين: ضرورة سيكولوجية باعتبارها تمارس تأثيرا ايجابيا

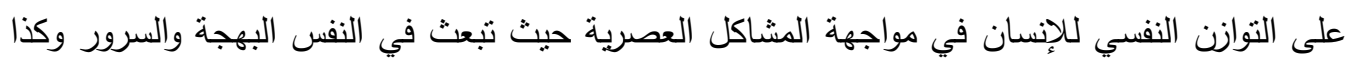

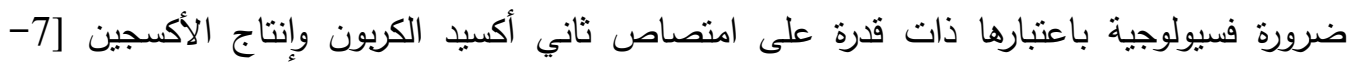
ص117].

إن علاقـة المبـاني المرتفعـة بـالموقع ومحاولــة تحقيـق فراغـات بينهـا جــبت انتبـاه بعض المعدـاريين

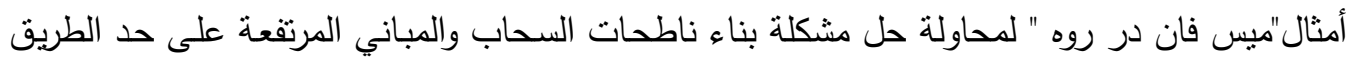

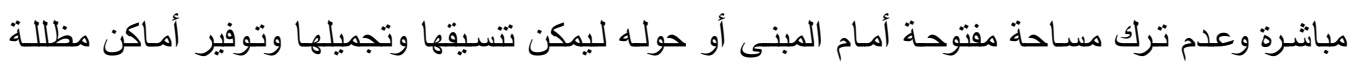

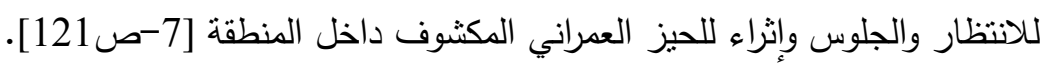

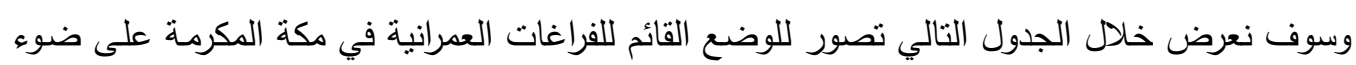

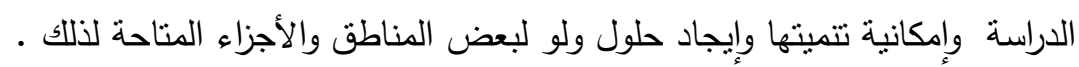


6- تصور الوضع القائم للفراغات العمرانية ومجالات تنميتها وذلك على النحو التالي:-

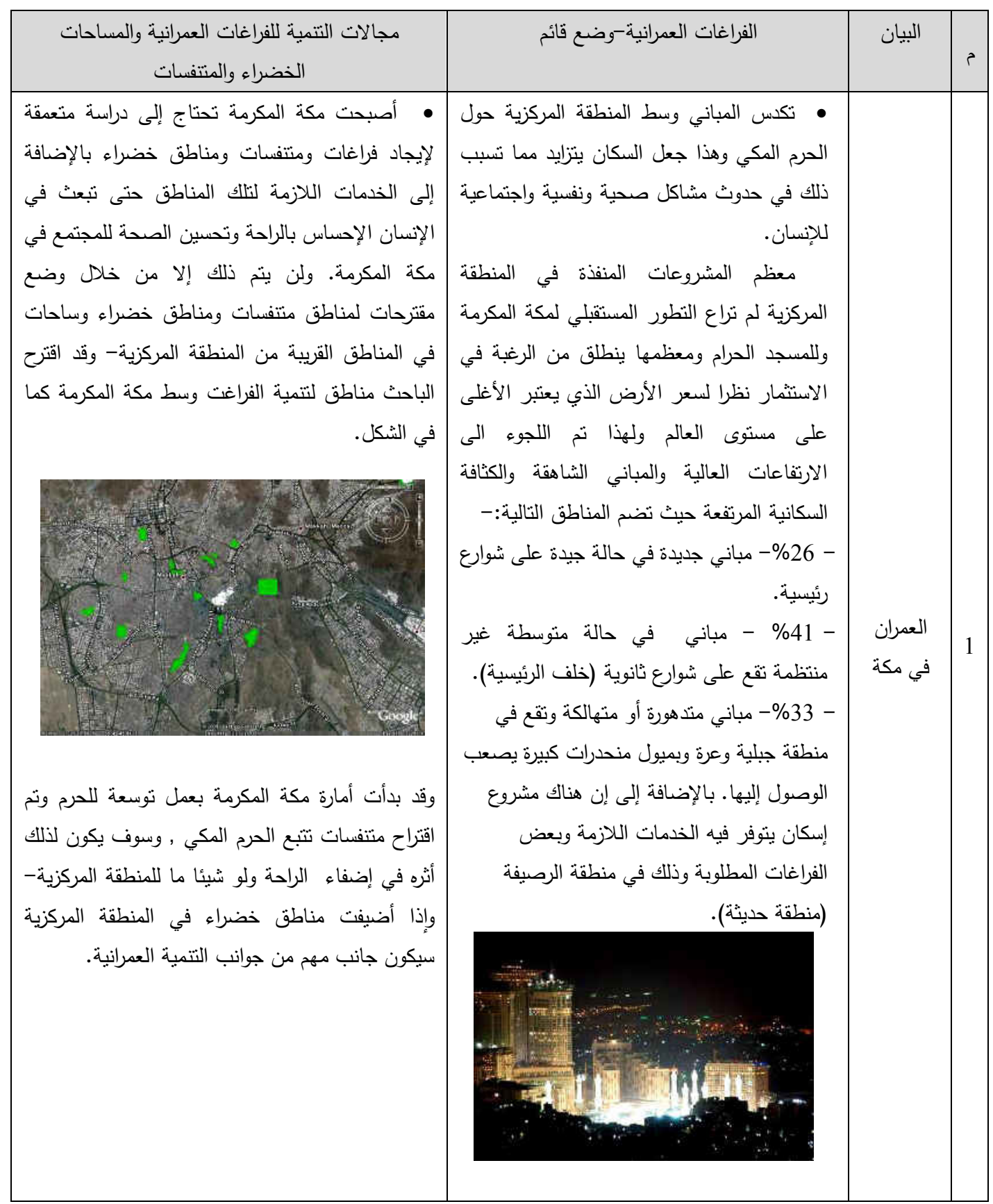




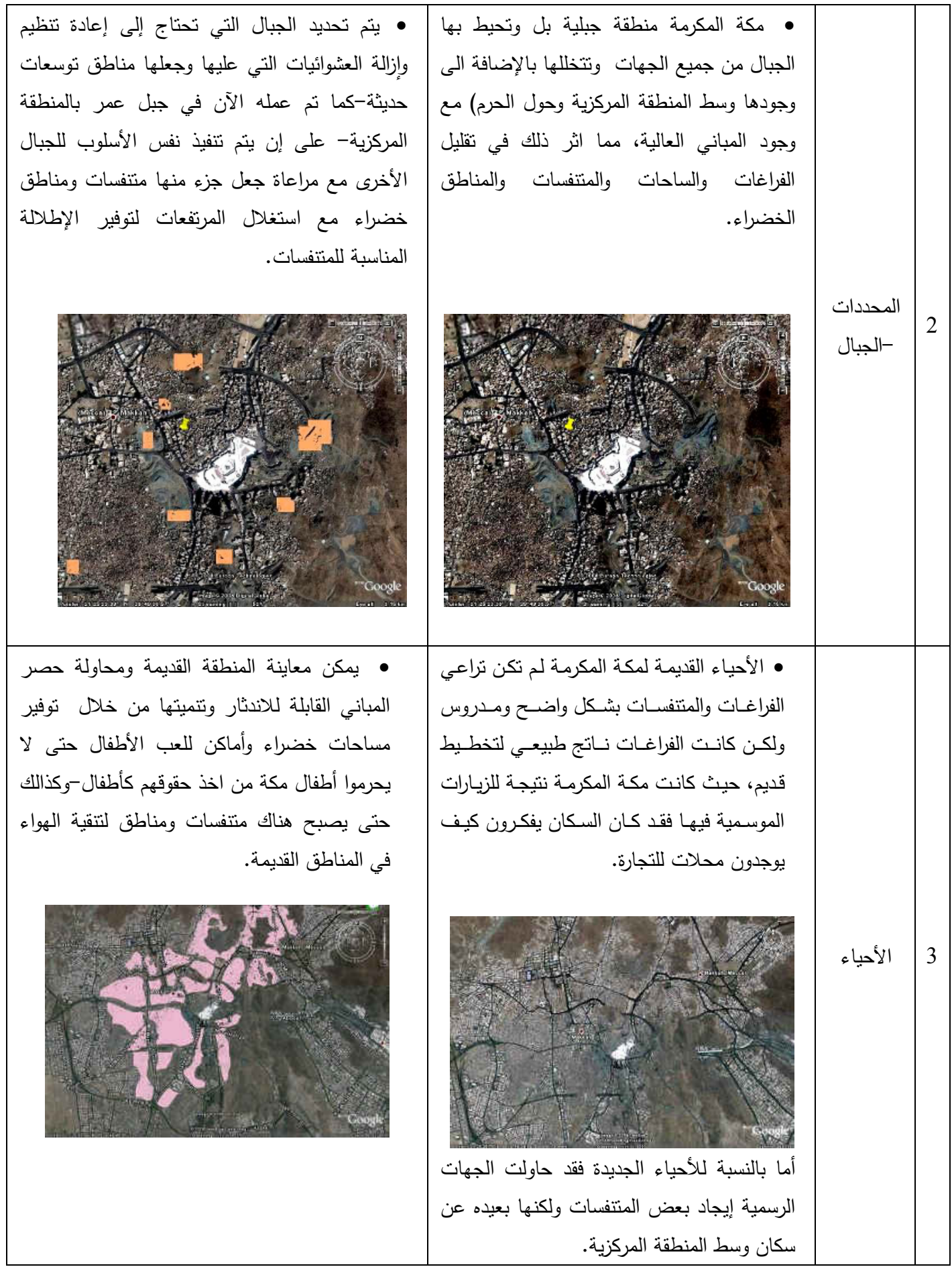




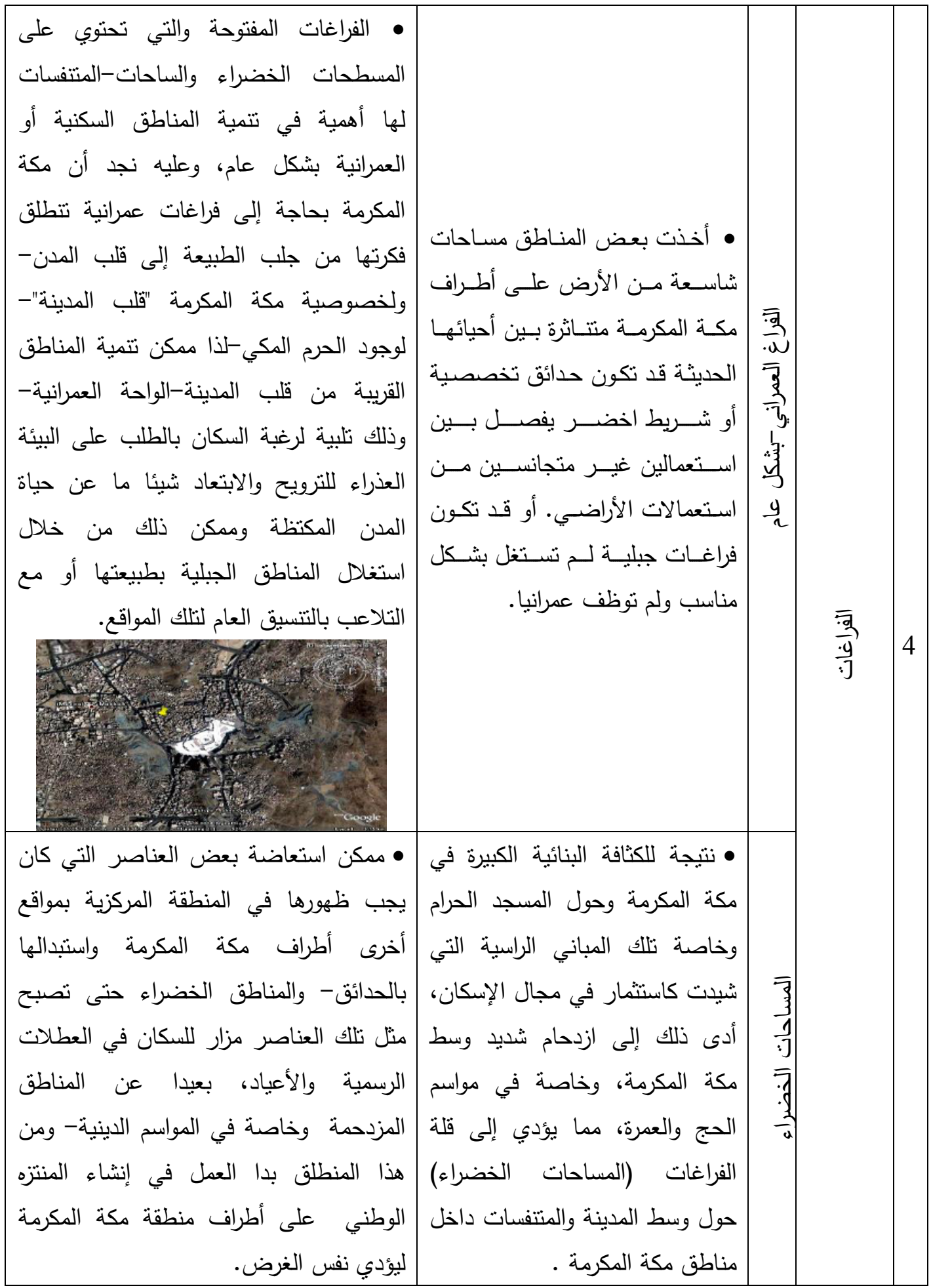


• مكة المكرمة تعتبر حالة فريدة •تتمية المناطق القربية من وسط المدينة من نوعها حيث أن المنطقة المركزية وخاصة المناطق التي تمثل فيها المباني المتدهورة والمتهالكة نسبة كبيرة و التي تقع في مناطق جبلية وعره وبميول ومنحدرات كبيرة -بالإضافة إلى تتمية مناطق في أطراف مكة المكرمة لتصبح مناطق متتفسات عامة ذات قيمة بيئية ايجابية للإنسان والمجتمع

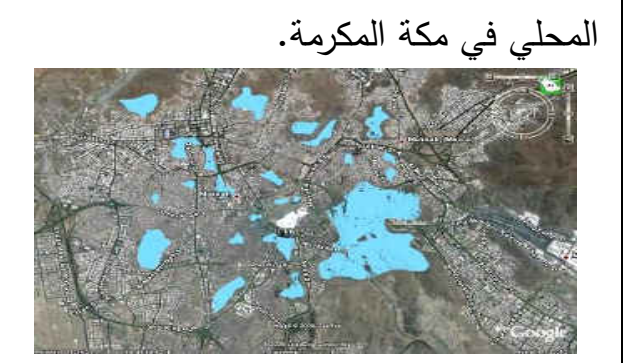

•توفير أماكن للعب الأطفال قربية من قلب فيها هي بؤرة للعبادة(على المستوى العربي والإسلامي وليس على مستوى المملكة فقط) وبهذا تكاد المتففسات فيها تكون معدومة نتيجة للاستثمارات العقارية في هذه المنطقة الأعلى تكلفة على المستوى المحلي والعالمي تقريبا.

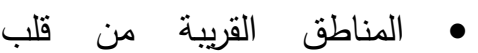
المدينة تفتقر إلى أماكن لعب العب الأطفال نتيجة للتكدس الحاصل فيها بسبب المنشآت العالية والكثيفة المدينة بحيث تتوفر فيها عوامل السلامة

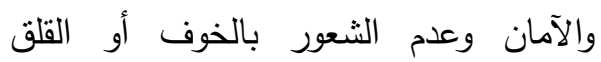
وتوفير عناصر الإضاءة ومراكز الخدمات العامة.

\section{-7 - النتائج والتوصيات.}

- من خـلال الدراسـة تبين لنا بعض المشكلات القائمة والناتجة عن تكدس المباني ذات الارتفاعات العالية وسط مكة المكرمة وفقدان الفراغات الداخلية للوسط، قد يكون ذلك ناتج عن وجود أعظم واشـرف مكان على وجـه الأرض فيها-الحرم المكي. فعلينا أن نتدارك الوضـع ونرشد التطور في البيئة العمرانيـة وخاصـة في المنـاطق المحيطـة بمركز مكـة المكرمـة مـن خـلال توفير الفراغـات

والمتنفسات فيها. - - الفراغ العمراني بشكل عام هو المورد الأساسي، ويمكن اعتباره ثروة قومية يجب أن توزع بحرص شـديد حتى لا تهدر هذه الثروة، إلا أن ذلك الأمـر بتطلب العنايـة في تقسيمه وتخصبص الحد الأقصى منه وإبقاء الحد الأدنى منه كفراغات عامة حتى ينال كل فرد نصيبه منه مباشرة مما يؤدي إلى اختفاء مفهوم الفراغ العمراني الشـامل في مشـاريع الإسكان وغيره من مشـاريع التتمية والذي تتخلله مباني عالية تتخللها شوارع ضيقة كما هو في مكة المكرمة. 
- - الفراغ العمراني في مشروعات الإسكان الجماعي يعتبر المورد الأساسي، وليس الكم الهائل من

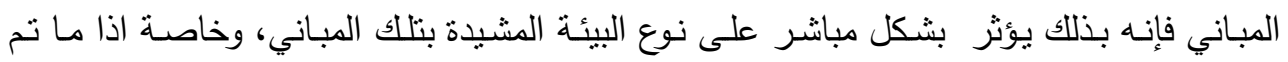

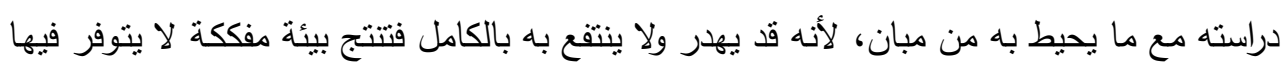

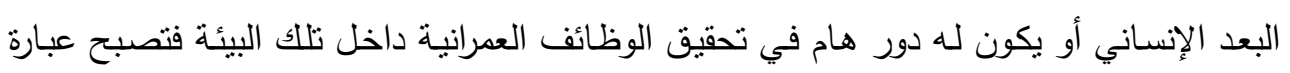

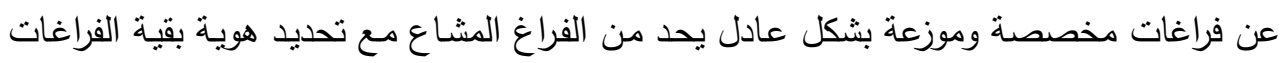
وذلك لتحقيق أقصى كفاءة في استخدامها كمورد أساسـي في التتـيـة عامـة وفي مكسة المكرمـة

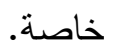
يمكن تصنيف الفراغات لتي تحتاج إليها مكة المكرمة ضمن فراغات الواحة العمرانية والتي تتبثق

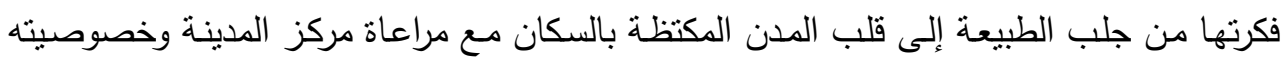
الدينية. - منطقة مكة المكرمة تتوسع في اتجاهات مختلفة وخاصـة خارج حدود وسط مكة دون مراعاة لاي

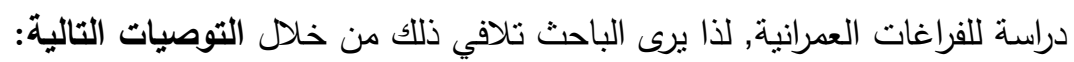
1. ضرورة تتمية مكة المكرمة بتوفير الفراغات العمرانية من خلال الآتي: إعادة النظر في المباني المتهالكة التي تثواجد وسط المناطق القديمـة وتعويض ملاكهـا والقيام

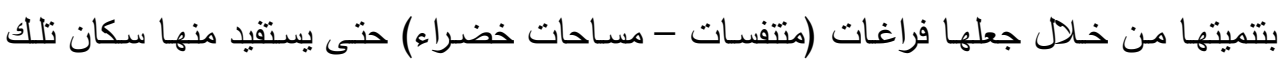
المناطق وتعمل على تجميل المنطقة بشكل عام.

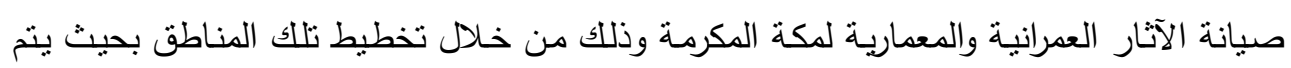

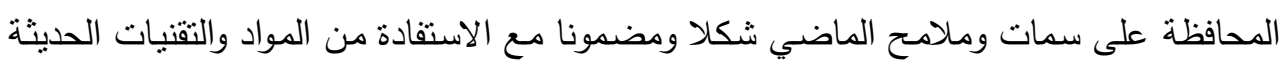
كما أن من تلاك العقارات المتهالكة ما قد يساعد في توسعة الحرم.

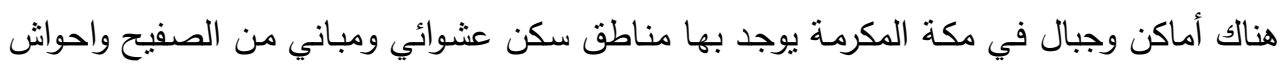

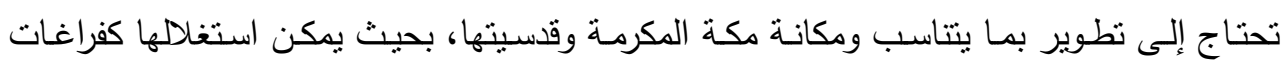
عمرانية مدروسة لنكون في خدمة سكان تلك المناطق وفي خدمة الحجاج والمعتمرين.

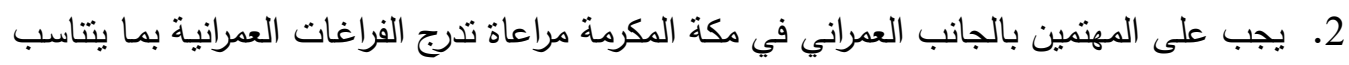

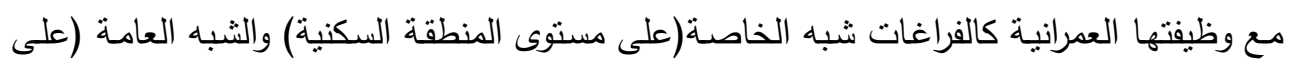

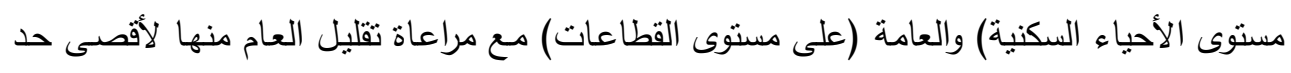

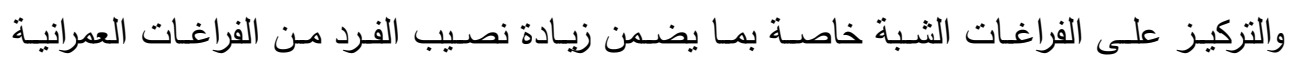

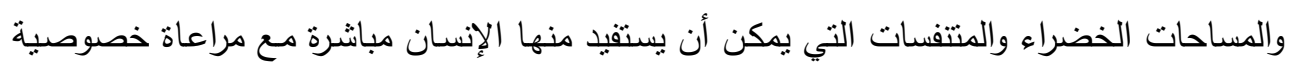


3. ضرورة التتسيق العام للفراغات والمساحات المفتوحة في مكة المكرمة مع ماهو قائم من كتل بنائية

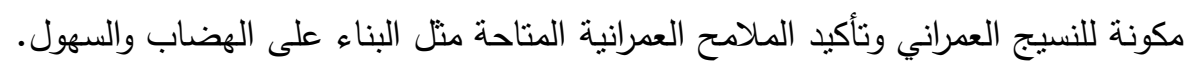

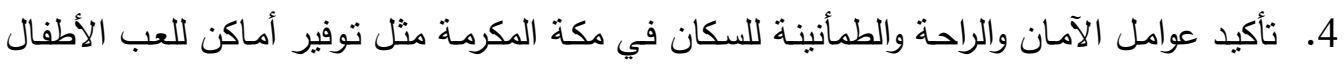

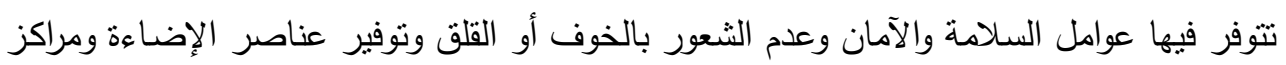

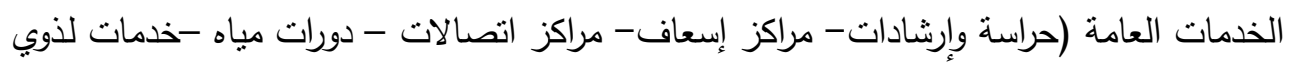

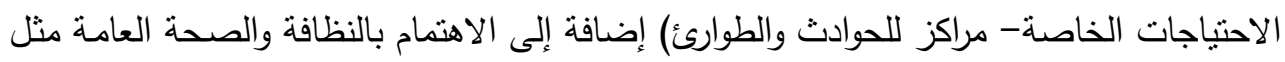

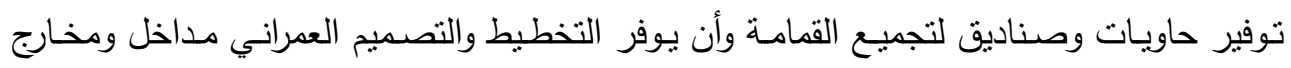
سهله لتجميع المخلفات وكيفية الاستفادة منها في خدمة البيئة .

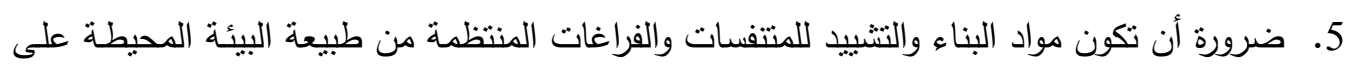

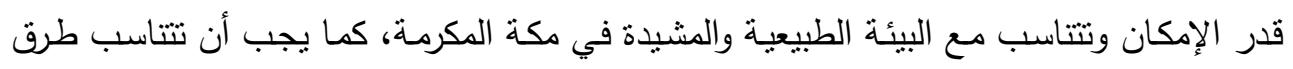

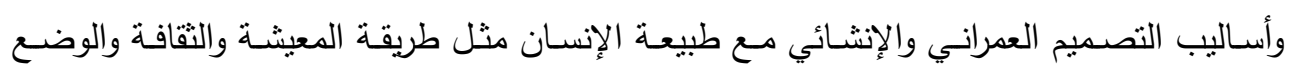

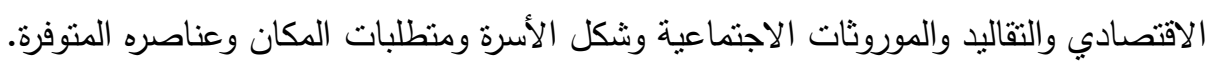

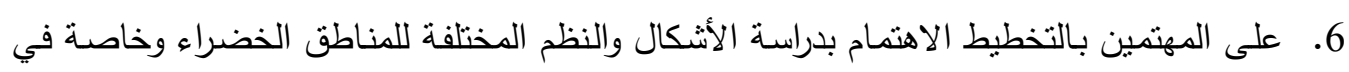

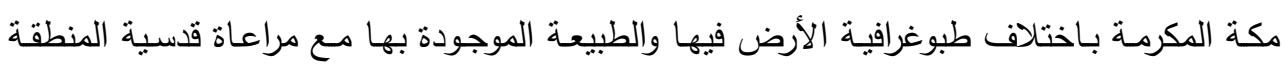

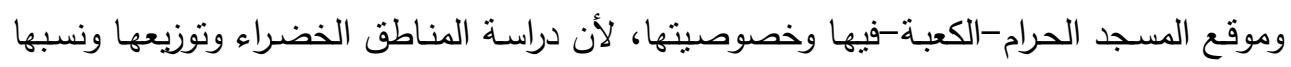
من العمليات الحيوية في تخطبط المدن.

\section{المراجع: نم التزميز لها في النص[ ]}

1- م. هشام محمود عارف- تتميه التجمعات السكنية في مصر كسالة الدكتوراه- جامعة القاهرة- كلية الهندسة- قسم الهندسة المعمارية 1995م.

2- مها صباح الزبيدي- المسكن المنوافق بيئيا..توجه مستقبلي للعمارة المستدامة والحفاظ على البيئةدراسة مقارنة لكفاءة الأداء البيئي للمسكن التقليدي والحديث-ندوة الإسكان الثانية(المسكن الميسر )

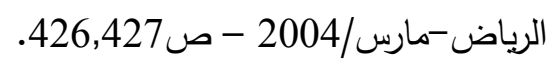

3- عبد الباقي إبراهيم-المنظور الإسـامي للتتمية العمرانية-مركز الدراسـات التخطيطية والمعماريةمصر -1983م.

4- تامر محمد عبد الفتاح-تتسيق المواقع كمدل لتصميم العناصر العمرانية بالمدن-رسالة ماجستير -

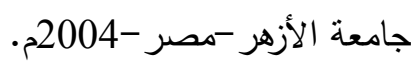

5- سهير زكي حواس-الفراغات العمرانية والمناطق المفتوحة كمورد وركيزة لتتمية المناطق السكنية في مصر .-رسالة دكتوراه-جامعة القاهرة-مصر - 1991م 
6- طلال بن حسن حمادي-تصميم الفراغات العمرانية المفتوحة للمدن الصحراوية- 1423هـ -جامعة

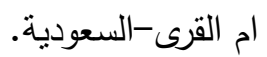

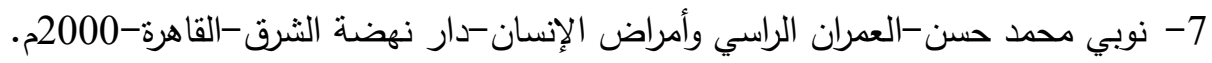

http://www.marefa.org/index.php/\%D9\%85\%D9\%83\%D8\%A9 -8

9- سامي برهمين-العوامل المؤثرة على تتفيذ مشاريع التشييد بمكة المكرمة-رسالة ماجستير -من جامعة

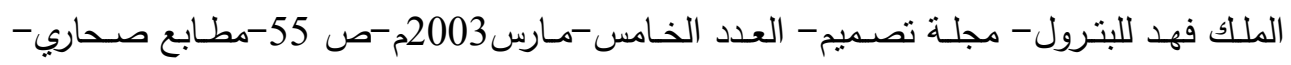

القاهره.

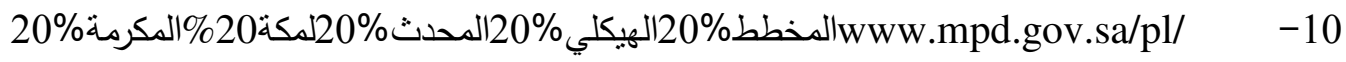

حتى 20\%ع-2008-6-6- ... (البحث عبر -google-عن-( الدخط الهيكلي المحدث لمكة المكرمة حتى عام 1450هـ)(11)

http://ar.wikipedia.org/wiki/\%D9\%85\%D9\%83\%D8\%A9_\%D8\%A7 -11 \%D9\%84\%D9\%85\%D9\%83\%D8\%B1\%D9\%85\%D8\%A9\#.D8.AD.D8.A7 .D8.B1.D8.A7.D8.AA_.D9.85.D9.83.D8.A9_.D8.A7.D9.84.D8.AA.D8.A7. D8.B1.D9.8A.D8.AE.D9.8A.D8.A9-21-5-2008

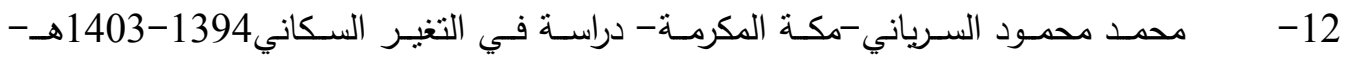

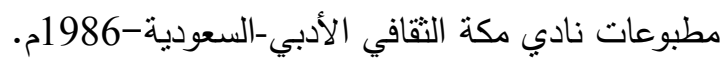

13- محد محمود السرياني -مكة المكرمة- دراسة في مخططات الأراضي - مطبوعات نادي

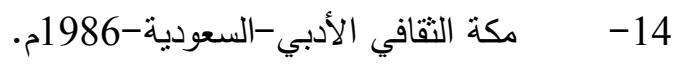

15- احمد محمد عبدالرحمن شحاته-تاصيل القيم المعمارية والعمرانية بمناطق الامتداد السكني بمكة

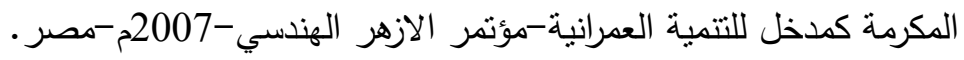

